\title{
Estimating leaf chlorophyll content in sugar beet canopies using millimeter- to centimeter-scale reflectance imagery
}

Sylvain Jay ${ }^{\mathrm{a}, \mathrm{b}, *}$, Nathalie Gorretta ${ }^{\mathrm{a}}$, Julien Morel ${ }^{\mathrm{a}}$, Fabienne Maupas ${ }^{\mathrm{c}}$, Ryad Bendoula ${ }^{\mathrm{a}}$, Gilles Rabatel $^{\mathrm{a}}$, Dan Dutartre ${ }^{\mathrm{c}}$, Alexis Comar ${ }^{\mathrm{d}}$, Frédéric Baret ${ }^{\mathrm{e}}$

${ }^{a}$ Irstea, UMR ITAP, 361 rue J.F. Breton, 34196 Montpellier, France

${ }^{b}$ Aix Marseille Univ, CNRS, Centrale Marseille, Institut Fresnel, F-13013 Marseille, France

${ }^{c}$ Institut Technique de la Betterave, 45 rue de Naples, 75008 Paris, France

${ }^{d}$ HIPHEN SAS, 22b rue Charrue, 84000 Avignon, France

e INRA UMR 114 EMMAH, UMT CAPTE, Domaine Saint-Paul, Site Agroparc, F-84914 Avignon, France

\section{Abstract}

Accurate estimation of leaf chlorophyll content $\left(C_{a b}\right)$ from remote sensing is of tremendous significance to monitor the physiological status of vegetation or to estimate primary production. Many vegetation indices (VIs) have been developed to retrieve $C_{a b}$ at the canopy level from meter- to decameter-scale reflectance observations. However, most of these VIs may be affected by the possible confounding influence of canopy structure. The objective of this study is to develop methods for $C_{a b}$ estimation using millimeter to centimeter spatial resolution reflectance imagery acquired at the field level.

Hyperspectral images were acquired over sugar beet canopies from a ground-based platform in the 400-1000 nm range, concurrently to $C_{a b}$, green fraction (GF), green area index (GAl) ground measurements. The original image spatial resolution was successively degraded from $1 \mathrm{~mm}$ to $35 \mathrm{~cm}$, resulting in eleven sets of hyperspectral images. Vegetation and soil pixels were discriminated, and for each spatial resolution, measured $C_{a b}$ values were related to various VIs computed over four sets of reflectance spectra extracted from the images (soil and vegetation pixels, only vegetation pixels, $50 \%$ darkest and brightest vegetation pixels). The selected VIs included some classical VIs from the literature as well as optimal combinations of spectral bands, including simple ratio $(S R)$, modified 
normalized difference $(m N D)$ and structure insensitive pigment index (SIPI). In the case of $m N D$ and SIPI, the use of a blue reference band instead of the classical near-infrared one was also investigated.

For the eleven spatial resolutions, the four pixel selections and the five VI formats, similar band combinations are obtained when optimizing VI performances: the main bands of interest are generally located in the blue, red, red-edge and near-infrared domains. Overall, $m N D_{\text {blue }}[728,850]$ defined as $\left(R_{440}-R_{728}\right) /\left(R_{440}+R_{850}\right)$ and computed over the brightest green pixels obtains the best correlations with $C_{a b}$ for spatial resolutions finer than $8.8 \mathrm{~cm}$ with a root mean square error of prediction better than $2.6 \mu \mathrm{g} / \mathrm{cm}^{2}$. Conversely, $m N D_{b l u e}[728,850]$ poorly correlates with variations in GF and GAI, thus reducing the risk of deriving non-causal relationships with $\mathrm{C}_{\mathrm{ab}}$ that would actually be due to the covariance between $C_{a b}$ and these canopy structure variables. As $m N D_{\text {blue }}[728,850]$ can be calculated from most current multispectral sensors, it is therefore a promising $\mathrm{VI}$ to retrieve $\mathrm{C}_{\mathrm{ab}}$ from millimeter- to centimeter-scale reflectance imagery.

Keywords : Leaf chlorophyll content, Millimeter to centimeter spatial resolutions, $\mathrm{mND}_{\text {blue }}$, Reflectance imagery, Vegetation index.

\section{Introduction}

Photosynthesis is one of the most important biological processes, allowing life on Earth through production of oxygen and organic matter (Ustin et al., 2009). Chlorophyll is one of the major plant pigments that contribute to the absorption of photosynthetically active radiation. Quantifying chlorophyll temporal dynamics is therefore critical to monitor the vegetation physiological status or to estimate primary production (Blackburn, 2007, 1998). For this purpose, non-destructive estimation of leaf chlorophyll content (denoted $\mathrm{C}_{\mathrm{ab}}$ hereafter) based on optical measurements has proven to be effective since $C_{a b}$ drives most of the leaf reflectance and transmittance variabilities in the visible domain. $A$ high $C_{a b}$ retrieval accuracy is usually obtained at the leaf scale under controlled experimental conditions, e.g., using dedicated leaf clips measuring transmittance at a few wavelengths (Cerovic et 
al., 2012), or using hemispherical reflectance and/or transmittance measurements to invert physical models such as PROSPECT (Jacquemoud and Baret, 1990) or to apply spectral indices (Gitelson et al., 2003; Féret et al., 2011; le Maire et al., 2004; ). The estimation of $C_{a b}$ is more challenging at the canopy scale: soil reflectance and canopy architecture interact with leaf scattering properties to generate canopy reflectance. As a consequence, the effect of leaf composition may be confounded with those of canopy structural properties, making the inversion of canopy reflectance models an ill-posed problem (Baret and Buis, 2008; Combal et al., 2003): several combinations of green area index (GAI) and $\mathrm{C}_{\mathrm{ab}}$ values may indeed correspond to similar canopy reflectance spectra in the visible domain, which increases the uncertainty of $C_{a b}$ retrieval (Baret and Buis, 2008). Further, non-causal relationships between canopy reflectance and the targeted variable may be observed when structural and biochemical variables are correlated as reported by Knyazikhin et al. (2013). Effects of canopy structure and leaf composition should therefore be disentangled with great care when relating remote-sensing observations to foliar biochemistry (Knyazikhin et al., 2013; Latorre-Carmona et al., 2014; Ustin, 2013).

A first approach has been proposed to improve the $C_{a b}$ estimation performance at the canopy level by maximizing the spectral sensitivity to foliar biochemistry while minimizing the effects of soil and vegetation structure. It consists in using a ratio vegetation index (VI), where the numerator is a $\mathrm{C}_{\mathrm{ab}}$-sensitive VI such the Modified Chlorophyll Absorption Reflectance Index (MCARI) (Daughtry et al., 2000), and the denominator is a VI sensitive to canopy structure such as the Optimized Soil-Adjusted Vegetation Index (OSAVI) (Rondeaux et al., 1996). MCARI/OSAVI (Daughtry et al., 2000), TCARI/OSAVI (Haboudane et al., 2002) and derived versions of these two Vls (Wu et al., 2008) are examples of such combined indices, which have been demonstrated to provide accurate $C_{a b}$ estimation results at the canopy level (Kooistra and Clevers, 2016).

Alternatively, a second approach consists in increasing the sensitivity to foliar biochemistry by optimizing the sun-sensor geometry: off-nadir measurements are generally more sensitive to leaf 
properties than nadir measurements (Baret et al., 2010; Comar et al., 2012; Dorigo, 2012; Jacquemoud et al., 2009; Jay et al., n.d.). This is not only due to the higher proportion of vegetation seen by the sensor, but also to the large fraction of photons that have interacted with leaves before reaching the sensor (Jacquemoud et al., 2009). Further, the relative viewing azimuth angle affects the canopy reflectance sensitivity: measurements acquired in the backward direction, where shadows are minimized, generally exhibit a higher sensitivity to leaf biochemistry (Dorigo, 2012; Jacquemoud et al., 2009; Jay et al., n.d.).

Finally, a third approach consists in focusing on the illuminated vegetation pixels when the spatial resolution is sufficient: this limits the detrimental influences of soil and canopy architecture and consequently strengthens the sensitivity to $C_{a b}$ (Moorthy et al., 2008; Zarco-Tejada et al., 2004, 2001). Multi- and hyperspectral cameras operated from ground-based or low-altitude platforms provide a very high spatial resolution, ranging from a few millimeters to a few decimeters. However, most current retrieval methods do not fully exploit the new possibilities offered by such high spatial resolution imagery, thereby stimulating the need for new algorithms (Elarab et al., 2015; Houborg et al., 2015). The large variability of leaf orientation and illumination conditions observed at this scale induces strong variations in leaf radiance. For example, Jay et al. (2016) have proposed to invert the PROSPECT+COSINE (ClOse-range Spectral ImagiNg of IEaves) model to map $\mathrm{C}_{a b}$ over individual leaves when the influence of surrounding elements is negligible. However, when individual leaves are submitted to the radiative transfer conditions that prevail in the canopy, the problem was not yet addressed. Most current VIs have been designed for leaf and canopy levels, and may therefore be suboptimal to handle the above-mentioned variations in leaf reflectance (Bånkestad and Wik, 2016).

This study focuses on $C_{a b}$ estimation in sugar beet canopies using millimeter- to centimeter-resolution reflectance imagery. Hyperspectral images were acquired from a ground-based platform and concurrent measurements of $\mathrm{GAl}$ and $\mathrm{C}_{\mathrm{ab}}$ were completed. These data were used to design Vls dedicated to $C_{a b}$ estimation that take advantage of such high spatial resolution imagery. Performances 
were compared to those obtained with several VIs of the literature for the range of spatial resolutions investigated.

\section{Materials and methods}

\subsection{Field experiments}

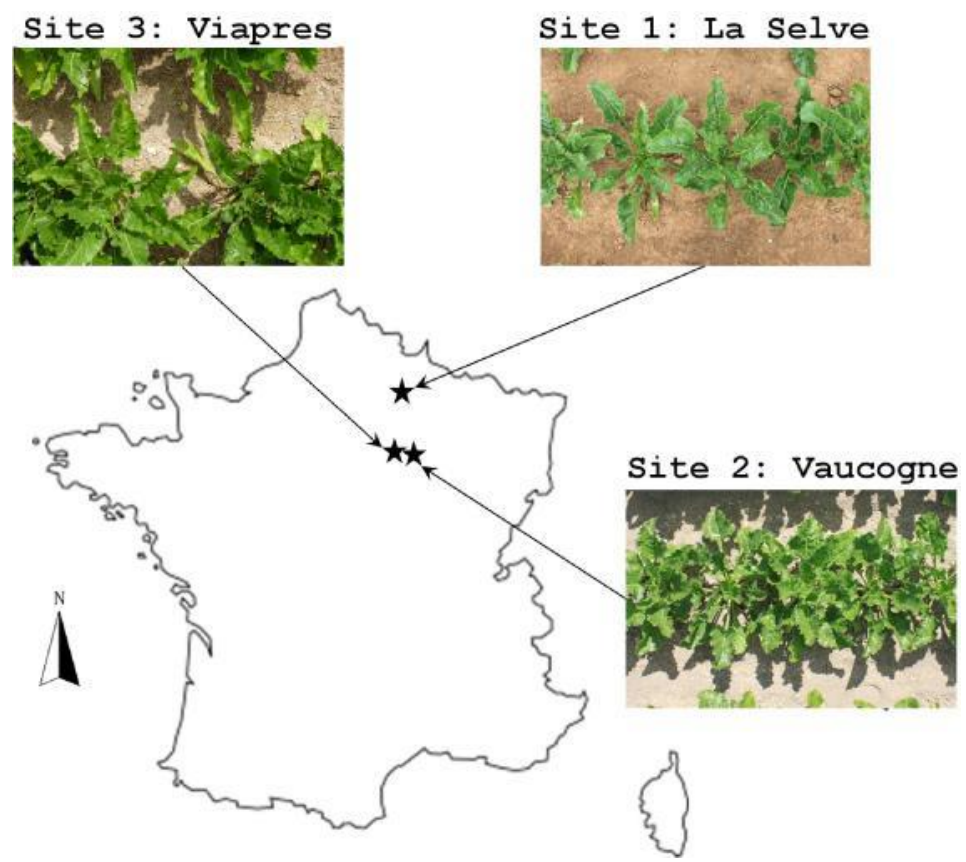

Figure 1: Locations of the three study sites and photographs of sugar beet canopies illustrating the encountered soil types (loamy soil for site 1 and chalky soil for sites 2 and 3 ).

Field experiments were conducted in France in 2015 and 2016. Three study sites with different soil properties were considered as illustrated in Fig. 1. A chalky soil was present at the "Vaucogne" $\left(48^{\circ} 31^{\prime} \mathrm{N}, 4^{\circ} 21^{\prime} \mathrm{E}\right.$, denoted site 2$)$ and "Viapres" $\left(48^{\circ} 35^{\prime} \mathrm{N}, 4^{\circ} 2^{\prime} \mathrm{E}\right.$, denoted site 3$)$ sites, while the "La Selve" site $\left(49^{\circ} 35^{\prime} \mathrm{N}, 4^{\circ} 01^{\prime} \mathrm{E}\right.$, denoted site 1$)$ was characterized by a loamy soil. The details of these field experiments are summarized in Table 1. Seven sugar beet cultivars exhibiting differences in plant structure were submitted to variable levels of nitrogen fertilization. Rows were spaced $45 \mathrm{~cm}$ apart and plant population density was between 10 to 12 plants per square meter. So as to further increase the representativeness and heterogeneity of the data set, various phenological stages were considered during the 2015 and 2016 growing seasons, i.e., on June, 2-3 2015, June, 23-24 2015 and July, 26-27 
2016. In particular, the crops considered in the 2016 experiment were carefully chosen so as to decorrelate $\mathrm{C}_{\mathrm{ab}}$ and canopy structural properties. In total, the overall data set included 55 samples and encompassed a large variability due to differences in cultivars, nitrogen fertilizations, development stages, and soil and weather conditions.

Table 1: Characteristics of field experiments. $\Theta_{s}$ is the sun zenith angle at the time of measurements.

\begin{tabular}{cccccc}
\hline Date & Site & $\Theta_{\mathrm{s}}\left(^{\circ}\right)$ & Illumination & Cultivar No. & $\begin{array}{c}\text { Number of } \\
\text { samples }\end{array}$ \\
\hline $06 / 02 / 2015$ & 2 & 36 & Clear & $1-3$ & 9 \\
$06 / 03 / 2015$ & 1 & 31 & Cloudy & $1-3$ & 9 \\
$06 / 23 / 2015$ & 1 & 29 & Partly cloudy & $1-3$ & 9 \\
$06 / 24 / 2015$ & 2 & 29 & Clear & $1-3$ & 9 \\
$07 / 26 / 2016$ & 3 & 33 & Clear & $4-6$ & 8 \\
$07 / 27 / 2016$ & 3 & 33 & Partly cloudy & 7 & 11 \\
\hline
\end{tabular}

\subsection{Reflectance measurements}

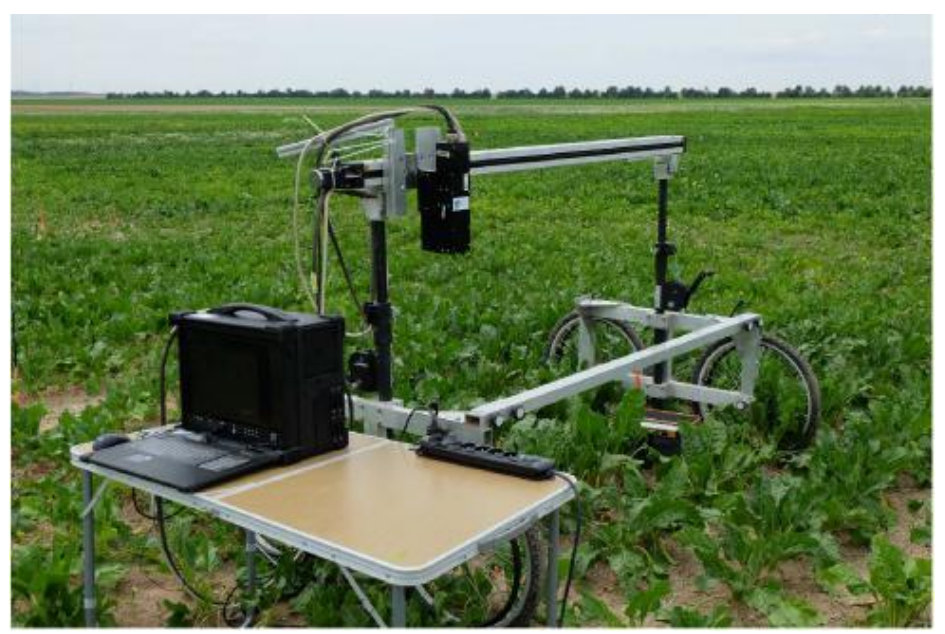

Figure 2: Ground-based platform used for hyperspectral measurements

For each plot, an area corresponding to five consecutive plants along a row was imaged using a HySpex VNIR-1600 hyperspectral camera (Norsk Elektro Optikk, Norway) set up on a ground-based platform 
as shown in Fig. 2. The push-broom camera pointed vertically downward from a $1.15 \mathrm{~m}$ distance to the bare soil. It measured the reflected radiation in 160 spectral bands ranging from 415 to $994 \mathrm{~nm}$ with a $3.7 \mathrm{~nm}$ spectral sampling interval and $4.5 \mathrm{~nm}$ full width at half maximum, and acquired successive scans of 1600 pixels along the row. The across-track field of view (FOV) was about $35 \mathrm{~cm}$ per scan at the ground level, providing a $0.02 \mathrm{~cm}$ across-track sampling distance. A $40 \%$ diffuse reflectance reference panel (Spectralon ${ }^{\circledR}$, Labsphere) was used to measure the incoming solar irradiance while limiting possible saturation of the sensor. The reference panel was placed horizontally above the canopy to reduce the influence of possible vicinity effects. The HDRF (Hemispherical-directional Reflectance Factor) was finally computed by dividing the signal measured for each band and each pixel over the target by that measured over the reference panel and multiplying it by the reflectance of the reference panel provided by Labsphere (assuming the panel to be Lambertian). Completion of the scans over the 5 plants took a few seconds during which the incoming radiation was supposed to be stable. Measurements were collected around solar noon with solar zenith angle always lower than $36^{\circ}$. Illumination conditions differed between experiments, ranging from a clear blue sky to a fully overcast sky (Table 1).

\section{3. $\quad C_{a b}$ and canopy structure measurements}

The leaf chlorophyll content was estimated for each plot after image acquisition over the same five plants. Six measurements per plant were made using a Dualex scientifict ${ }^{\mathrm{TM}}$ (Force-A, Orsay, France). This leafclip measures leaf transmittance in a few wavebands from which $C_{a b}$ is estimated using the relationship proposed by Cerovic et al. (2012) for dicotyledons, achieving an accuracy of around $4 \mu \mathrm{g} . \mathrm{cm}^{-2}$. Measurements were performed at different leaf levels to better consider the possible $C_{a b}$ vertical gradient between leaves of different age or differently located in the canopy. These thirty $C_{a b}$ values were averaged to provide a single $C_{a b}$ value per plot. After $C_{a b}$ measurements, the five plants were collected and the area of each individual leaf measured using a photography-based technique. The GAI was finally obtained by multiplying the average leaf area per plant by the plant population 
density. In addition, the green fraction (GF, the fraction of green elements seen by the sensor in its view direction) was estimated from hyperspectral images using the discrimination method detailed in Section 2.4.2.

Inspection of the co-distributions between $\mathrm{C}_{\mathrm{ab}}$ and $\mathrm{GAl}$, and between $\mathrm{C}_{\mathrm{ab}}$ and GF shows very poor correlations in both cases (Fig. 3). Incidentally, note the importance of the 2016 data that enable these correlations to be significantly reduced. The independency between $\mathrm{C}_{\mathrm{ab}}$ and GAI (resp. GF) distributions prevents from obtaining spurious empirical relationships between VIs and $C_{a b}$ that may be inherited from a more causal relationship between VIs and GAI (resp. GF).
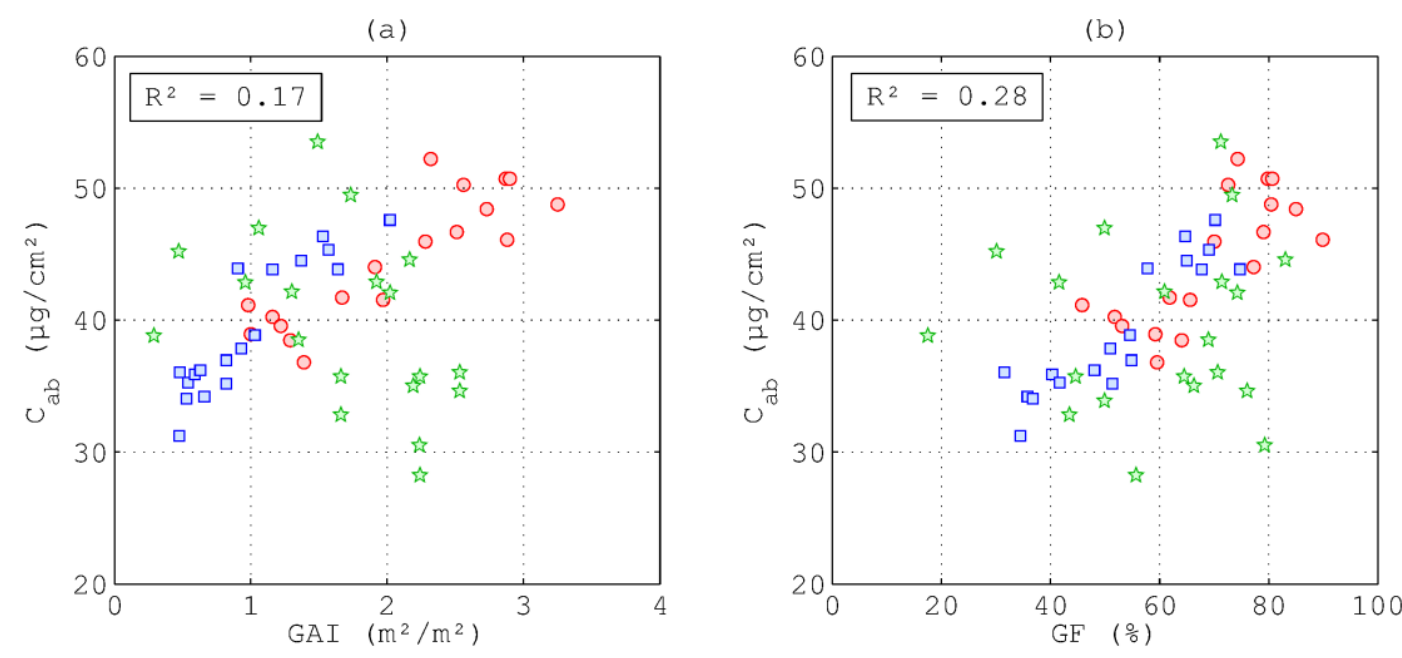

$$
\begin{aligned}
& \text { une, 2-3 } 2015 \\
& \text { June, 23-24 } 2015 \\
& \text { 기y, 26-27 } 2016
\end{aligned}
$$

\begin{tabular}{|cc|}
\hline & Unit \\
\hline Cab & $\mu \mathrm{g} / \mathrm{cm}^{2}$ \\
$\mathrm{GAI}$ & $\mathrm{m}^{2} / \mathrm{m}^{2}$ \\
$\mathrm{GF}$ & $\frac{\circ}{0}$ \\
\hline
\end{tabular}

$\begin{array}{ccc}\text { Min / Max } & \text { Mean } & \text { Std } \\ 28.1 / 53.4 & 41.1 & 6.0 \\ .29 / 3.25 & 1.58 & 0.76 \\ 17 / 90 & 61 & 16\end{array}$

Figure 3: $\mathrm{C}_{\mathrm{ab}}, \mathrm{GAl}$ and $\mathrm{GF}$ reference measurements. 


\subsection{Processing of radiometric data}

\subsubsection{Image spatial subsampling}

The performance of $C_{a b}$ estimation was evaluated over a range of spatial resolutions. The original spatial resolution of $0.02 \mathrm{~cm}$ was degraded to $0.1,0.2,0.4,0.9,1.8,3.5,4.4,7,8.8,17.5$ and $35 \mathrm{~cm}$ by averaging over cells of $\mathrm{NxN}$ pixels. This resulted in eleven sets of hyperspectral images as illustrated in Fig. 4.

(a)

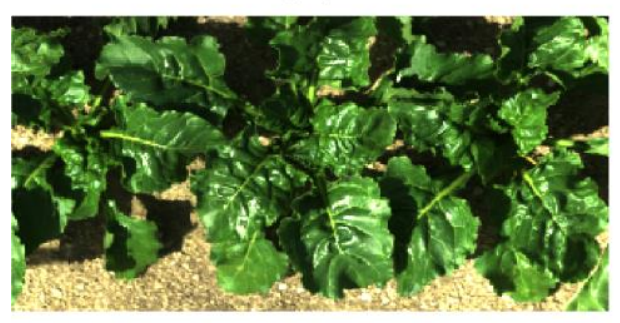

(c)

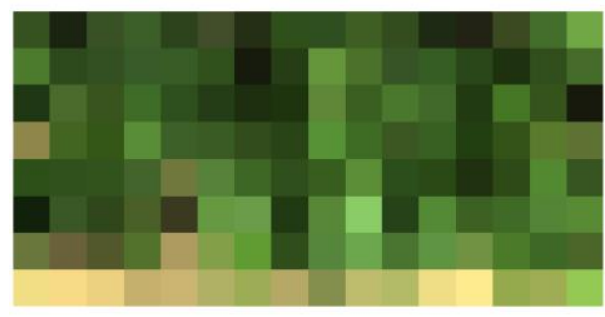

$(e)$

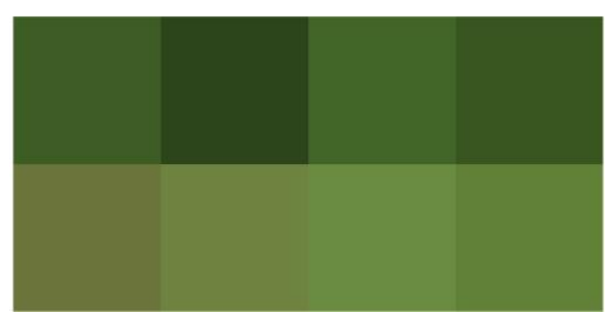

(b)

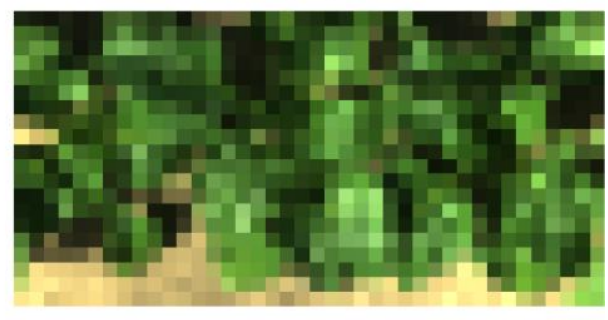

(d)

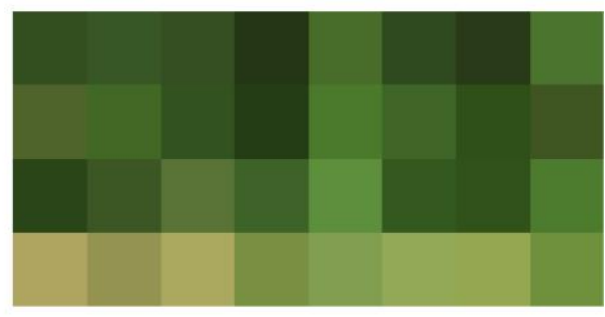

(f)

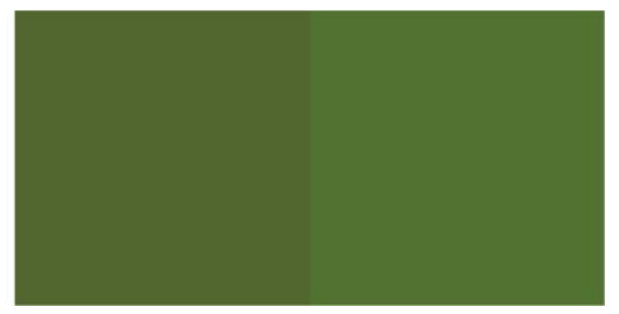

Figure 4: Gradual degradation of spatial resolution. Illustration for (a) $0.1 \mathrm{~cm}$, (b) $1.8 \mathrm{~cm}$, (c) $4.4 \mathrm{~cm}$, (d) $8.8 \mathrm{~cm}$, (e) $17.5 \mathrm{~cm}$ and (f) $35 \mathrm{~cm}$.

\subsubsection{Discrimination of soil and vegetation}

VIs were not only used to estimate $C_{a b}$, but also to discriminate green vegetation from senescent elements and soil. Preliminary tests (not further developed here for the sake of brevity, but illustrated in the figure provided in supplementary material) demonstrated that the modified version of MCARI 
proposed by Wu et al. (2008) and defined as MCARI[705,750] $=\left[\left(R_{750}-R_{705}\right)-0.2\left(R_{750}-\right.\right.$ $\left.\left.R_{550}\right)\right] \frac{R_{750}}{R_{705}}$ provided the best discrimination performance as compared to the other Vls investigated (Table 2). MCARI[705,750] is designed to minimize the effects of soil and non-photosynthetic materials, and its discrimination capacity appeared to be little dependent on soil properties and illumination conditions. Further, as illustrated in Fig. 5b and Fig. $5 \mathrm{~g}$ for strongly different soil properties and illumination conditions, a single threshold value of $\operatorname{MCARI}[705,750]=0.34$ ensured accurate discrimination performance at the $0.1 \mathrm{~cm}$ spatial resolution, for which the fraction of mixed pixels was negligible (note that GF was estimated at this resolution). The fraction of mixed pixels significantly increased when the resolution degraded, making the classification more difficult. The MCARI $[705,750]$ threshold value was thus adjusted for each resolution investigated to keep the GF similar to that computed with the $0.1 \mathrm{~cm}$ spatial resolution. The threshold value was therefore increased as the spatial resolution degraded in order to compensate for the increase in the number of mixed pixels (Fig. 5).
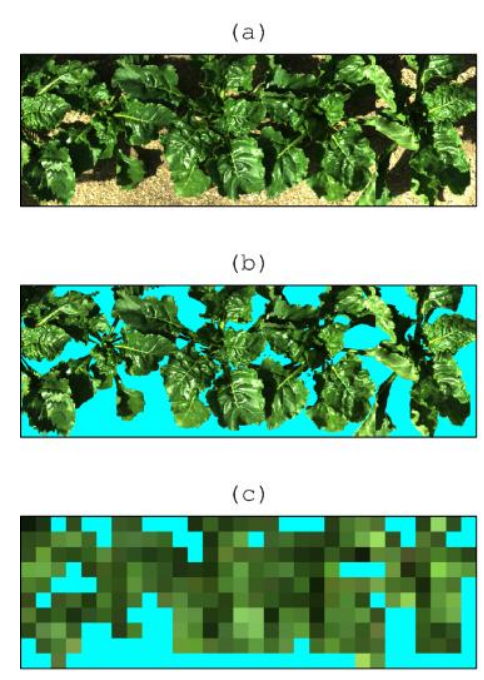

(d)
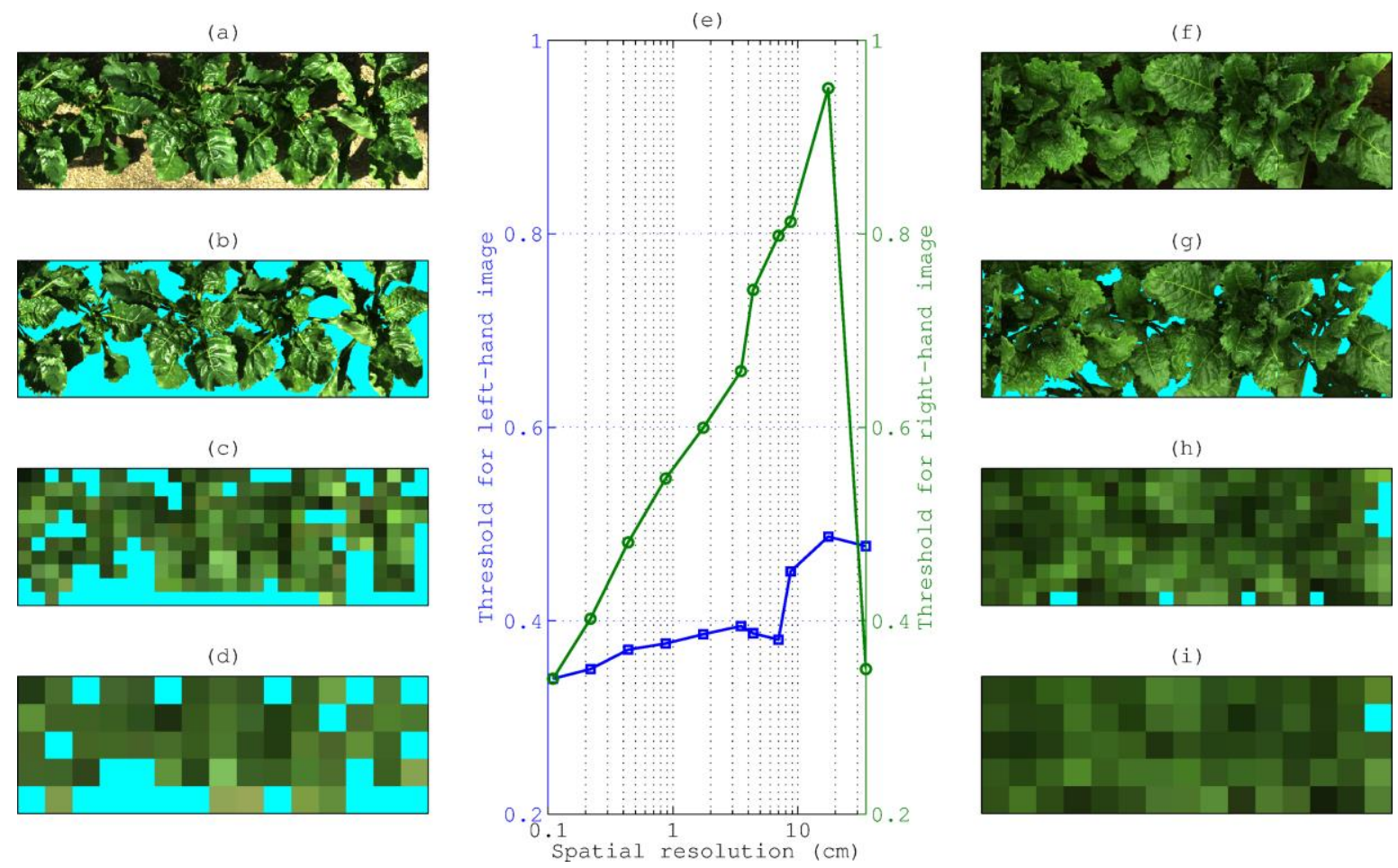

(h)

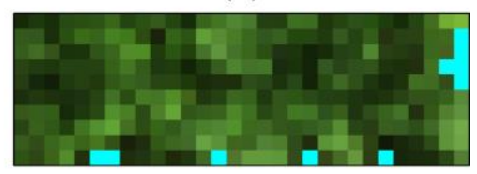

(i)

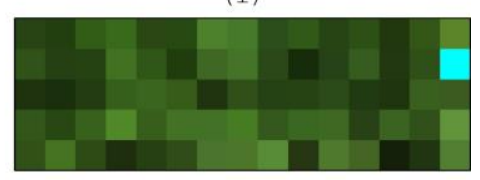

Figure 5: Discrimination results obtained from two contrasted situations, i.e., low GF with chalky soil and under sunny conditions (a), and large GF with loamy soil and under cloudy conditions (f). The same MCARI[705,750] threshold value is used for the finest $(0.1 \mathrm{~cm})$ spatial resolution $(b, g)$. This threshold is then adjusted for 
coarser resolutions to keep the same GF (e). The resulting discrimination results are presented for 3.5 (c,h) and $7 \mathrm{~cm}(\mathrm{~d}, \mathrm{i})$ spatial resolutions. Masked soil pixels are colored in cyan.

\section{5. $C_{a b}$ estimation}

\subsubsection{Selection of vegetation indices}

Several VIs were selected from the literature to estimate $C_{a b}$. All of them are ratios based on two or three wavebands located in the $400-900 \mathrm{~nm}$ spectral domain (Table 2). They are potentially sensitive to $\mathrm{C}_{\mathrm{ab}}, \mathrm{GF}$, and GAI. VIs computed as ratios of linear combinations of bands present the advantage to minimize the possible influence of multiplicative factors, including slope effects and variations in illumination conditions when the radiance measurements on the reference panel and on the target are not performed concurrently. These ratio VIs may be split into three different categories as presented in Table 2.

The simplest one, SR (Simple Ratio), corresponds to the ratio of reflectance in two wavebands: a band, hereafter denoted $\lambda_{1}$, that is sensitive to both absorption by chlorophyll and scattering by leaf, and a reference band, denoted $\lambda_{\text {ref }}$, that is only sensitive to scattering in order to correct from this effect (Blackburn, 2007). For example, $C I_{\text {green }}$ and $C I_{\text {red-edge }}$ (Gitelson et al., 2006, 2005, 2003) are based on simple ratios, and combine a near-infrared reference band with a band located in medium chlorophyll absorption domains to avoid saturation in $\mathrm{C}_{\mathrm{ab}}$. Both $C I_{\text {green }}$ and $C I_{\text {red-edge }}$ have been found to provide accurate estimates of $C_{a b}$ at the leaf level (Gitelson and Merzlyak, 1994; Gitelson et al., 2003, 2006; Schlemmer et al., 2013) and canopy chlorophyll content at the canopy level (Gitelson et al., 2005; Clevers and Kooistra, 2012; Clevers and Gitelson, 2013; Schlemmer et al., 2013).

VIs from the second category are based on modified Normalized Difference ratios ( $m N D$ ), for which a third waveband, denoted $\lambda_{2}$, can be introduced at the denominator. Note that SR and $m N D$ are functionally related when $\lambda_{1}=\lambda_{2}$, since $m N D=(1-S R) /(1+S R)$. Alternatively, taking $\lambda_{2} \neq \lambda_{1}$ may increase the sensitivity to $C_{a b}$ while reducing the impact of canopy structure and soil background 
properties. $N D_{550}$ (Gitelson et al., 1996), $N D_{705}$ (Gitelson and Merzlyak, 1994) and $N D V I$ (Rouse et al., 1973) are examples of $m N D$ indices.

A simple modification of $m N D$ indices, i.e., SIPI (Structure Insensitive Pigment Index) was proposed by Rondeaux and Vanderbilt (1993) and Penuelas et al. (1995) to decrease the confounding influence of leaf surface as well as canopy structure effects (Bousquet et al., 2005; Vigneau et al., 2011; Comar et al., 2014; Jay et al., 2016). For SIPI-like indices, various reference bands have been proposed: for example, Sims and Gamon (2002) have demonstrated that using a blue saturating waveband as reference within $m S R$ (modified Simple Ratio) may increase the $C_{a b}$ estimation performance as compared to SR indices. MTCI (MERIS Terrestrial Chlorophyll Index) proposed by Dash and Curran (2004) is also a SIPI-like index, where the three bands used are conveniently located in the red-edge spectral domain, the reference band $(709 \mathrm{~nm})$ being close to the red one.

Because of the diversity of bands used to compute the three types of VIs as outlined in Table 2, the data set presented in Section 2 was used to find optimal sets of wavebands in the case of millimeterto centimeter-scale reflectance imagery of sugar beet canopies. Similarly to Penuelas et al. (1995) and Inoue et al. (2012), $C_{a b}$ prediction performance of these three VIs were evaluated for every possible combination of $\lambda_{1}$ and $\lambda_{2}$ bands between 415 and $900 \mathrm{~nm}$ by $3.7 \mathrm{~nm}$ step. $C_{\mathrm{ab}}$ prediction performances were assessed using the Spearman's rank correlation coefficient, denoted $\rho$. As compared to using the usual Pearson's coefficient, $R$, using $\rho$ reduces the influence of possible non-linearities between VIs and $\mathrm{C}_{\mathrm{ab}}$ as well as between Dualex readings and actual $\mathrm{C}_{\mathrm{ab}}$ values. In the case of $S R$ that uses only two wavebands, the reference band was also varied systematically from 415 to $900 \mathrm{~nm}$, and $S R$ indices were thus noted $S R\left[\lambda_{1}, \lambda_{2}\right]$. In the cases of $m N D$ and $S I P I$ indices, as the reference waveband should be insensitive to $C_{a b}$ variations over the considered $C_{a b}$ range, it was set either to near infrared (850 $\mathrm{nm}$ ) or to blue (440 nm). The corresponding Vls were thus noted respectively $m N D_{\text {nir }}\left[\lambda_{1}, \lambda_{2}\right]$ and $S I P I_{\text {nir }}\left[\lambda_{1}, \lambda_{2}\right]$ if $\lambda_{\text {ref }}=\lambda_{\text {nir }}=850 \mathrm{~nm}$, and $m N D_{\text {blue }}\left[\lambda_{1}, \lambda_{2}\right]$ and $S I P I_{\text {blue }}\left[\lambda_{1}, \lambda_{2}\right]$ if $\lambda_{\text {ref }}=\lambda_{\text {blue }}=$ $440 \mathrm{~nm}$. Note that, although the atmosphere has lesser influence on the measured signal when using 
low altitude sensors (e.g., ground- or tower-based, or embedded on unmanned aerial vehicles (UAVs)) instead of classical satellite- and airborne sensors, the reflected radiation in the blue domain may strongly vary with changes in illumination conditions caused by atmospheric absorption and scattering. This implies that the use of $m N D_{\text {blue }}\left[\lambda_{1}, \lambda_{2}\right]$ and $S I P I_{\text {blue }}\left[\lambda_{1}, \lambda_{2}\right]$ requires a particular attention to properly convert the measured radiance into reflectance. Also, if necessary due to the lower sensitivity of $C C D$ sensors in the blue region, the signal-to-noise ratio may be increased by aggregating a few wavebands around $440 \mathrm{~nm}$.

Table 2: Vegetation indices selected from the literature and their generic formulation.

\begin{tabular}{|c|c|c|c|c|c|c|}
\hline $\begin{array}{l}\text { Generic } \\
\text { VI name }\end{array}$ & $\begin{array}{c}\mathrm{VI} \\
\text { formulation }\end{array}$ & $\lambda_{\text {ref }}$ & $\lambda_{1}$ & $\lambda_{2}$ & Actual VI name & References \\
\hline$S R$ & $\frac{R_{\lambda_{1}}}{R_{\lambda_{\text {ref }}}}$ & $\begin{array}{l}780 \\
780\end{array}$ & $\begin{array}{l}550 \\
710\end{array}$ & - & $\begin{array}{c}C I_{\text {green }}=S R-1 \\
C I_{\text {red-edge }}=S R-1\end{array}$ & $\begin{array}{l}\text { Gitelson et al. (2005, } \\
2003,2006)\end{array}$ \\
\hline$m N D$ & $\frac{R_{\lambda_{r e f}}-R_{\lambda_{1}}}{R_{\lambda_{\text {ref }}}+R_{\lambda_{2}}}$ & $\begin{array}{l}800 \\
750\end{array}$ & $\begin{array}{l}670 \\
550\end{array}$ & $\begin{array}{l}670 \\
550\end{array}$ & $\begin{array}{l}N D V I \\
N D_{550}\end{array}$ & $\begin{array}{l}\text { Rouse et al. (1973) } \\
\text { Gitelson et al. (1996) } \\
\text { Gitelson and Merzlyak } \\
\text { (1994) }\end{array}$ \\
\hline SIPI & $\frac{R_{\lambda_{\text {ref }}}-R_{\lambda_{1}}}{R_{\lambda_{\text {ref }}}-R_{\lambda_{2}}}$ & $\begin{array}{l}445 \\
709\end{array}$ & 754 & $\begin{array}{l}705 \\
681\end{array}$ & $\begin{array}{l}m S R \\
M T C I\end{array}$ & $\begin{array}{l}\text { Penuelas et al. (1995) } \\
\text { Sims and Gamon (2002) } \\
\text { Dash and Curran (2004) }\end{array}$ \\
\hline
\end{tabular}

\subsubsection{Estimation procedure}

Every tested VI was related to the measured $C_{a b}$ values using the 55 images, the strength of the relationship being quantified based on the squared Spearman's correlation coefficient, $\rho^{2}$. This process was applied for each spatial resolution using four subsets of reflectance spectra. (1) For the first subset, all pixels were used, i.e., including both soil and vegetation parts. (2) In the second subset, only green 
pixels were used. These vegetation pixels were then sorted according to their brightness level computed as the average reflectance value in the $770-900 \mathrm{~nm}$ spectral domain. This allowed us to define the two last subsets, corresponding to (3) the $50 \%$ darkest green pixels, and (4) the $50 \%$ brightest green pixels. Such pixel selections influence the impact of canopy structure on VIs as reported by Zarco-Tejada et al. (2001). Furthermore, two strategies were considered to compute the VI average value over selected pixels: either (1) reflectance spectra were first averaged over all pixels of the subset and the VI was then calculated, or (2) the VI was first computed for each pixel of the subset and the resulting VI values were then averaged. As VIs are generally non-linear functions of reflectance, these two strategies may lead to different results if the images are heterogeneous (Steven et al., 2015). The performance of $\mathrm{C}_{\mathrm{ab}}$ estimation were thus evaluated for the eleven spatial resolutions, the four subsets of pixels and the two VI averaging strategies, resulting into 88 regressions for each VI. Ultimately, linear and best non-linear relationships between $\mathrm{C}_{\mathrm{ab}}$ and best VIs were determined. Prediction performances for each relationship were then quantified based on the coefficient of determination $\left(R^{2}\right)$ and the root mean square error of prediction (RMSEP), both being estimated using a leave-one-out cross-validation process because of the relatively small number of images available.

In addition, the same procedure was applied for GF and GAI estimations since the considered VIs are also potentially sensitive to these structural variables.

\section{Results and discussion}

In the following, the selection of optimal sets of wavebands to compute the VIs is first investigated. These optimized VIs are then compared to the classical ones presented in Table 2 based on their relationships with $\mathrm{C}_{\mathrm{ab}}$, GF and $\mathrm{GAl}$, especially emphasizing the effects of spatial resolution and pixel selections.

\subsection{Optimal band selection for $\mathrm{C}_{\mathrm{ab}}$ estimation from vegetation indices}


Because of the multidimensional aspect of this study and the associated complexity for reporting the results in an exhaustive way, emphasis is put on $0.9 \mathrm{~cm}$ and $17.5 \mathrm{~cm}$ spatial resolutions that illustrate two contrasted situations. Further, only the results obtained by computing VIs from average reflectance spectra of vegetation pixels are presented. Very similar results were observed for the other spatial resolutions, subsets of pixels and when computing VIs by averaging pixel-level VI values. For the sake of brevity, these results are not presented in this article.

For every VI, similar patterns of $\rho^{2}$ squared Spearman's correlation coefficient are observed for the two spatial resolutions investigated (Fig. 6). The maximum values are obtained for very similar combinations of $\left[\lambda_{1}, \lambda_{2}\right]$ wavebands. However, the $0.9 \mathrm{~cm}$ spatial resolution provides generally higher $\rho^{2}$ values as well as slightly broader patterns of high correlations as compared to the $17.5 \mathrm{~cm}$ resolution. The largest difference between the two spatial resolutions occurs for the $S I P I_{\text {nir }}$ in the yellow to red domains where soil and vegetation reflectances show the largest contrast. In this case, the higher proportion of mixed pixels significantly degrades the correlations with $\mathrm{C}_{\mathrm{ab}}$. Symmetrical patterns are observed for $S R$ and $S I P I$ indices, since $S R\left[\lambda_{1}, \lambda_{2}\right]=1 / S R\left[\lambda_{2}, \lambda_{1}\right]$ and $\operatorname{SIPI}\left[\lambda_{1}, \lambda_{2}\right]=$ $1 / \operatorname{SIPI}\left[\lambda_{2}, \lambda_{1}\right]$. Conversely, non-symmetrical patterns are observed for $m N D$ indices that do not verify this property.

For $S R\left[\lambda_{1}, \lambda_{2}\right]$, the best performances are obtained taking $\lambda_{1}$ in the red-edge (between 710 and 735 $\mathrm{nm})$ and $\lambda_{2}$ having a longer wavelength. The highest correlation is observed for $S R[732,884]$, which is close to the $C I_{\text {red edge }}$ proposed by Gitelson et al. $(2005,2003,2006)$. Selecting a red-edge band actually increases the sensitivity to $C_{a b}$ variation for high $C_{a b}$ values, i.e., it minimizes the saturation effect. For $m N D_{\text {nir }}\left[\lambda_{1}, \lambda_{2}\right]$, the best performances are obtained choosing $\lambda_{1}$ in the red-edge and $\lambda_{2}$ in the red-edge and near infrared domains, i.e., $R_{\lambda_{2}} \approx R_{\lambda_{\text {nir }}}$. For such waveband combinations, we have $m N D_{\text {nir }}\left[\lambda_{1}, \lambda_{\text {nir }}\right] \approx 1-S R\left[\lambda_{1}, \lambda_{\text {nir }}\right] \approx C I_{\text {red edge }}$. A convergence is thus reached between these two generic Vls when optimizing the set of wavebands for $C_{a b}$ estimation. Anyway, the highest correlation 


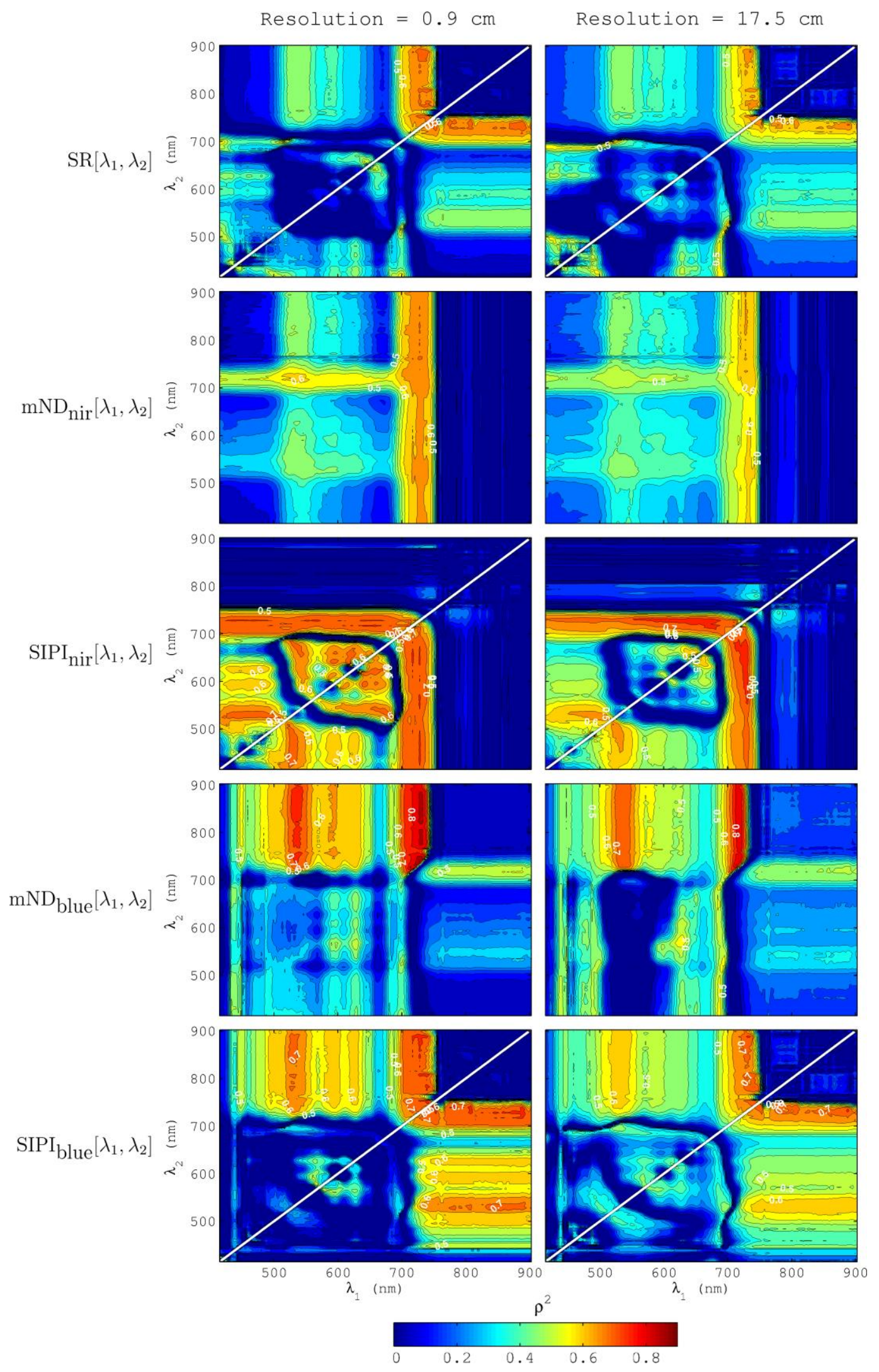

Figure 6: Squared Spearman's correlation $\left(\rho^{2}\right)$ obtained between VIs and $C_{a b}$ as a function of $\lambda_{1}$ and $\lambda_{2}$ wavebands. VIs are computed from average reflectance spectra of vegetation pixels for the $0.9 \mathrm{~cm}$ (lefthand column) and $17.5 \mathrm{~cm}$ (right-hand column) spatial resolutions. The five generic VIs are considered, i.e., $S R\left[\lambda_{1}, \lambda_{2}\right], m N D_{\text {nir }}\left[\lambda_{1}, \lambda_{2}\right], S I P I_{\text {nir }}\left[\lambda_{1}, \lambda_{2}\right], m N D_{\text {blue }}\left[\lambda_{1}, \lambda_{2}\right]$, and $S I P I_{\text {blue }}\left[\lambda_{1}, \lambda_{2}\right]$ from top to bottom. The color scale is the same for the five VIs and the two spatial resolutions. 
is obtained for $m N D_{\text {nir }}[732,850]$. For $S I P I_{\text {nir }}\left[\lambda_{1}, \lambda_{2}\right]$, the best performances are observed for $\lambda_{1}$ in the red-edge and $\lambda_{2}$ in the green to red domains, the optimal combination being $\operatorname{SIPI}_{\text {nir }}[728,670]$. This VI is similar to the original SIPI (Penuelas et al., 1995) with the exception of the use of a red-edge band at the numerator instead of a blue band, which reduces possible saturation effects for the considered $\mathrm{C}_{\mathrm{ab}}$ range. Note that no bands are selected in the near-infrared range since the reference band is already in this domain. For $m N D_{b l u e}\left[\lambda_{1}, \lambda_{2}\right]$, the best performances are observed for $\lambda_{1}$ in the red-edge and $\lambda_{2}$ in the red-edge and near-infrared domains. Note that taking $\lambda_{1}$ in the green range (around $533 \mathrm{~nm}$ ) also provides strong correlations, especially at $0.9 \mathrm{~cm}$ spatial resolution. In addition to the blue band used as a reference, the bands showing the largest contrast in chlorophyll absorption coefficients are selected. Unlike the other Vls tested, the best $\mathrm{C}_{\mathrm{ab}}$-sensitive waveband slightly differs between the two spatial resolutions, ranging from $728 \mathrm{~nm}$ at $0.9 \mathrm{~cm}$ to $717 \mathrm{~nm}$ at $17.5 \mathrm{~cm}$. Since the best performances are obtained for $\lambda_{1}=728 \mathrm{~nm}, m N D_{\text {blue }}[728,850]$ is selected for further analysis. Finally, for $S I P I_{\text {blue }}\left[\lambda_{1}, \lambda_{2}\right]$, the maximum correlations are obtained taking $\lambda_{1}$ in the red-edge and $\lambda_{2}$ in the NIR plateau for the same reasons as those involved for $m N D_{\text {blue }}$. The optimal waveband combination is $S I P I_{\text {blue }}[728,888]$, whose expression mainly differs from the $m S R$ index proposed by Sims and Gamon (2002) by the use of a longer $C_{a b}$-sensitive waveband.

\subsection{Sensitivity to $C_{a b}$}

The VI sensitivity to $\mathrm{C}_{\mathrm{ab}}$ (in terms of $\rho^{2}$ ) is shown in Fig. 7 for the classical VIs presented in Table 2 as well as the five optimized VIs designed in Section 3.1. These VIs are computed for the eleven spatial resolutions, the four subsets of pixels and the two strategies to compute the VIs. 


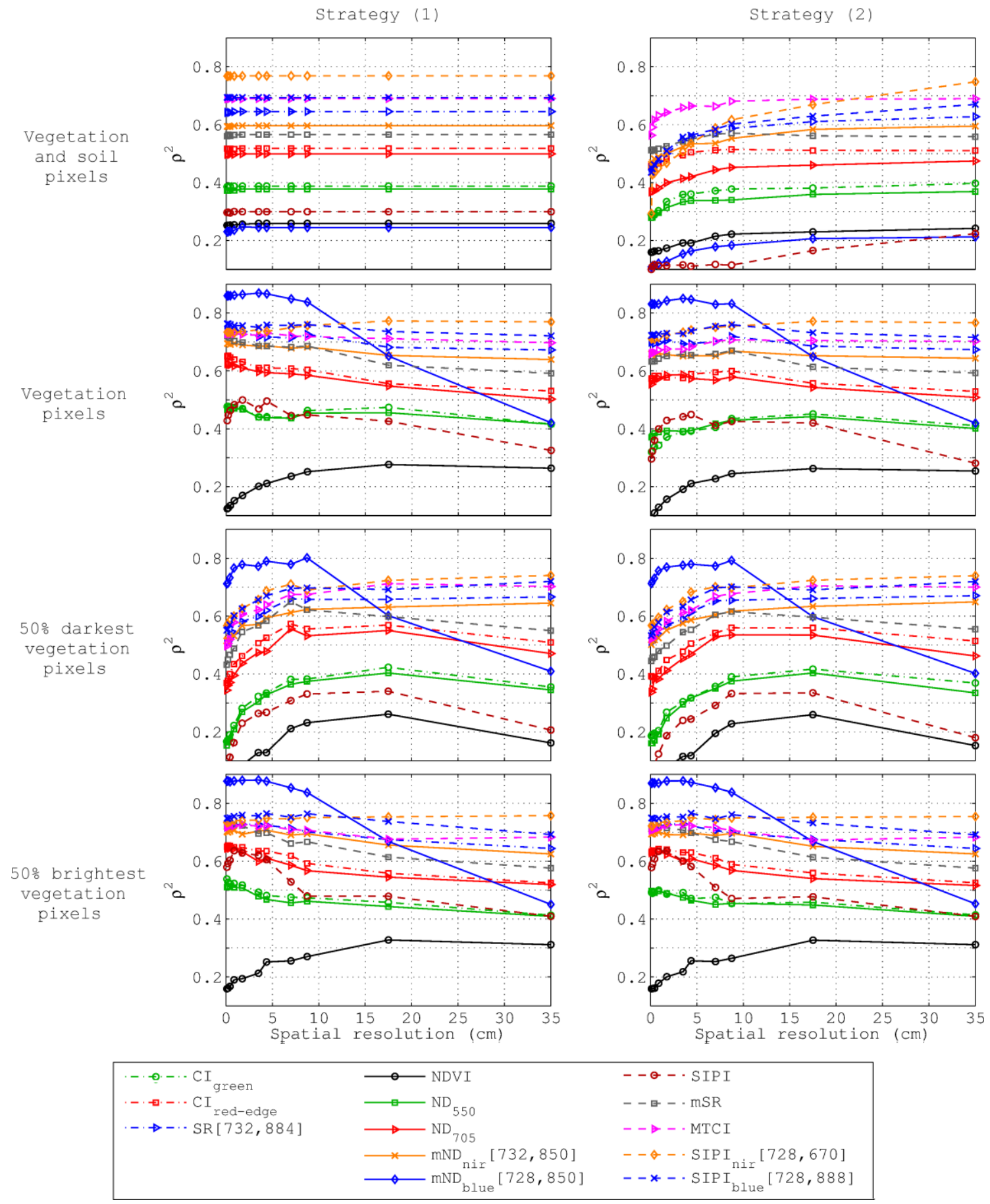

Figure 7: Squared Spearman's correlation $\left(\rho^{2}\right)$ between VIs and $C_{a b}$ measured over the 55 plots as a function of spatial resolution. In the left-hand column, VIs are computed from the average reflectance spectra of considered pixels (strategy (1)), while in the right-hand column, VIs are computed by averaging pixel-level $\mathrm{VI}$ values (strategy (2)). For both strategies, the four subsets of pixels are tested (vegetation and soil pixels, vegetation pixels, $50 \%$ darkest and brightest vegetation pixels). 
Comparing the two strategies for computing VI values from images shows that the differences mainly depend on the level of heterogeneity within the considered pixels. The heterogeneity increases as the spatial resolution increases and the pixel selection becomes less restrictive (in order, $50 \%$ darkest or brightest green pixels, green pixels, all the pixels). When the level of heterogeneity is the largest, as when considering all the pixels in the case of high resolution (Fig. 7, line 1), averaging first the reflectance values over the pixels and then computing the $\mathrm{VI}$ (Strategy 1 ) provides better $\mathrm{C}_{\mathrm{ab}}$ estimation performances than Strategy 2 (averaging the VI values computed for each individual pixel). This may be due to the fact that averaging the reflectances put more weight on the brightest pixels that bear more reliable information on $\mathrm{C}_{\mathrm{ab}}$ as demonstrated later. Conversely, computing first the VIs at the pixel level may lead to unrealistic VI values when the pixels have low reflectance values: since VIs are computed as ratios, low values in the denominator will provide unstable values. Note that, since the average reflectance value in the image does not depend on spatial resolution, the performances do not change with spatial resolution when computing Vls from the average reflectance spectra over all the pixels (Fig. 7, top left-hand plot). When the distribution of pixel values is reduced as in the case of medium to coarse spatial resolution for a restricted selection of pixels (green pixels, $50 \%$ darkest or brightest green pixels), the two strategies lead to very similar results (Fig. 7, lines 2-4).

Only Strategy 1 will therefore be considered in the following since it provides either best or equal $C_{a b}$ estimation performances as Strategy 2.

When all the pixels are considered (Fig. 7, line 1), the best-performing VI is $\operatorname{SIPI}_{\text {nir }}[728,670]\left(\rho^{2}=\right.$ $0.77)$, followed by $S I P I_{\text {blue }}[728,888]$ and $M T C I\left(\rho^{2}=0.69\right)$. A substantial improvement is observed for every VI except NDVI when considering only vegetation pixels, especially for spatial resolutions finer than $8.8 \mathrm{~cm} . m N D_{\text {blue }}[728,850]$ obtains significantly higher correlations than other VIs with $\rho^{2}$ ranging from 0.84 to 0.87 for resolutions finer than $8.8 \mathrm{~cm}$. Again, the SIPI VIs show good correlations, with $\operatorname{SIPI}_{\text {blue }}[728,888], \operatorname{SIPI}_{\text {nir }}[728,670]$ and $M T C I$ achieving $\rho^{2}$ close to 0.74 for the finest resolutions. Incidentally, it is worth noting that, even if $M T C I$ was originally designed for estimating 
canopy chlorophyll content from low-resolution satellite sensors (Dash and Curran, 2004), the good performances obtained here are consistent with those observed in previous studies dealing with leaf chlorophyll content estimation from higher resolution remote sensing (Haboudane et al., 2008; Hunt et al., 2012; Jay et al., n.d.). While the performances obtained with most VIs remain nearly stable when the resolution degrades, those obtained with $m N D_{\text {blue }}[728,850]$ drop down to $\rho^{2}=0.42$ at $35 \mathrm{~cm}$ spatial resolution. This indicates that $m N D_{\text {blue }}[728,850]$ is very sensitive to the soil influence observed in mixed pixels. In the case of coarse spatial resolutions for which vegetation and soil cannot be accurately discriminated, using a shorter wavelength more sensitive to $C_{a b}$ for $\lambda_{1}$ is expected to improve the performances by mitigating the soil influence as discussed earlier (Fig. 6).

Considering the $50 \%$ brightest green pixels (Fig. 7, line 4) generally improves the performances of $C_{a b}$ estimation for every resolution as compared to using all the green pixels (Fig. 7, line 2). In particular, $m N D_{\text {blue }}[728,850]$ reaches $\rho^{2}=0.88$ for resolutions finer than $4.4 \mathrm{~cm}$, while $\operatorname{SIPI}_{\text {blue }}[728,888]$ and $S I P I_{\text {nir }}[728,670]$ led to $\rho^{2}=0.76$ and $\rho^{2}=0.74$ respectively. The benefit of considering only the brightest green pixels for $C_{a b}$ estimation is in agreement with previous findings (Moorthy et al., 2008; Zarco-Tejada et al., 2004, 2001). Conversely, using the $50 \%$ darkest pixels results in lower correlations, especially for the highest spatial resolutions. For those pixels, the incoming radiation contains a higher proportion of photons that have already interacted with the canopy before reaching the considered leaves. This may make the illumination conditions locally very variable, leading to lower correlations with $C_{a b}$. 
(a)

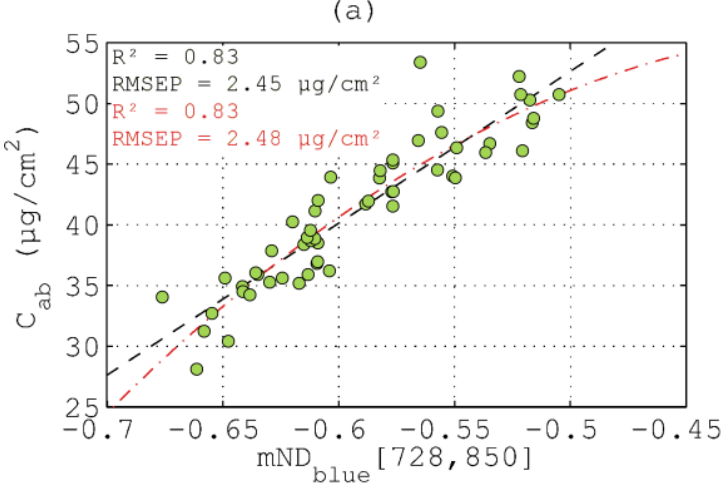

(c)

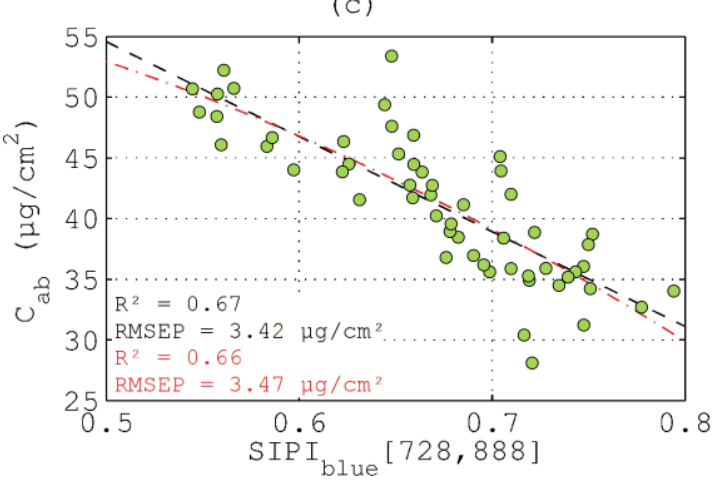

(b)

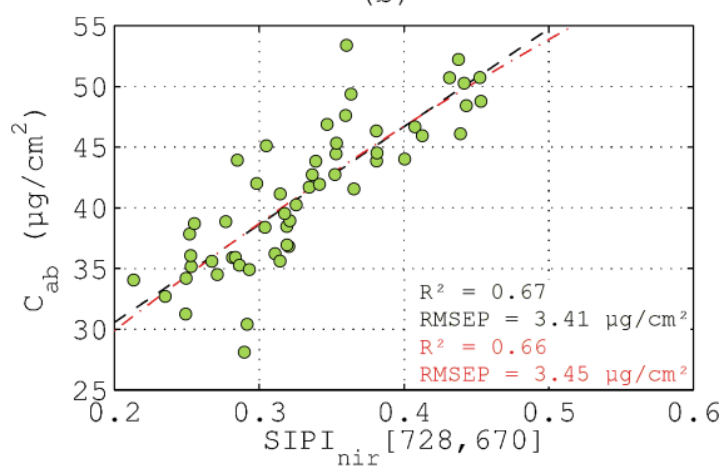

(d)

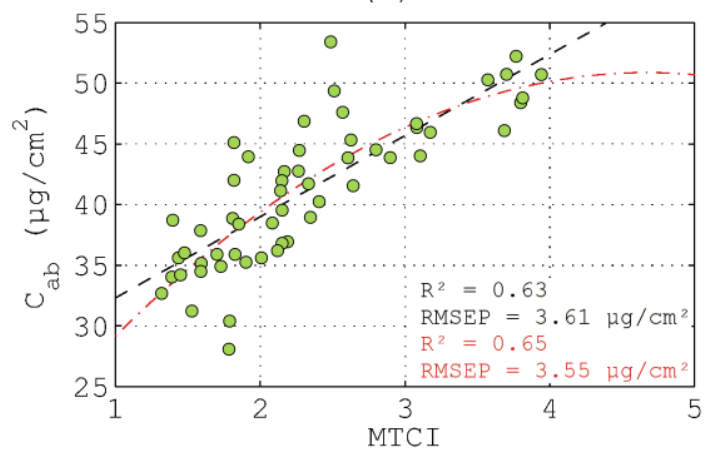

Figure 8: Relationships between $\mathrm{C}_{\mathrm{ab}}$ and (a) $m N D_{\text {blue }}[728,850]$, (b) $\operatorname{SIPI_{\text {nir}}}[728,670]$, (c) $\operatorname{SIPI} I_{\text {blue }}[728,888]$, and (d) $M T C I$. The spatial resolution is $3.5 \mathrm{~cm}$, and VIs are computed from average reflectance spectra of the $50 \%$ brightest vegetation pixels. For each $\mathrm{Vl}$, the prediction performances obtained using linear (in black) and best non-linear (second-degree polynomials, in red) regressions are shown.

The best cases are analyzed in more detail to better quantify their performances (Fig. 8). They correspond to $m N D_{b l u e}[728,850], \operatorname{SIPI}_{\text {blue }}[728,888], \operatorname{SIPI}_{\text {nir }}[728,670]$ and MTCI computed from the average reflectance spectra of the $50 \%$ brightest green pixels observed at the $3.5 \mathrm{~cm}$ spatial resolution. $m N D_{\text {blue }}[728,850]$ achieves the best performances with $R^{2}=0.83$ and $R M S E P=2.45$ $\mu \mathrm{g} / \mathrm{cm}^{2}$ (i.e., $9.6 \%$ of $C_{a b}$ range) using a linear regression model, while the non-linear regression model does not improve the results. The three other best VIs lead to significantly lower estimation performances, ranging from $R^{2}=0.67$ and $R M S E P=3.41 \mu \mathrm{g} / \mathrm{cm}^{2}(13.4 \%)$ for $\operatorname{SIPI}_{\text {nir }}[728,670]$ to $R^{2}=0.65$ and $R M S E P=3.55 \mu \mathrm{g} / \mathrm{cm}^{2}(14.0 \%)$ for MTCI. These RMSEP values are about $40 \%$ higher than that obtained with $m N D_{\text {blue }}[728,850]$. Note that these RMSEP values should be reassessed by using more accurate $C_{a b}$ measurements as obtained from a pigment extraction method instead from transmittance-based Dualex measurements. 


\subsection{Sensitivity to GF and GAI}

As mentioned earlier, VIs may be simultaneously sensitive to variations in $\mathrm{C}_{\mathrm{ab}}$ and canopy structural variables such as GF or GAl. The effect of leaf biochemical composition must therefore be carefully disentangled from that of structural variables.

For this purpose, the correlation between the tested VIs and GF (Fig. 9) or GAI (Fig. 10) was investigated. For both structural variables, the performances of the two strategies to compute the Vls similarly depend on the level of heterogeneity in the pixel selection. However, unlike for $C_{a b}$, when the heterogeneity is the largest, as when considering all the pixels at the highest resolutions, averaging the pixel-level VI values (Strategy 2) generally provides slightly better correlations with both GF and GAI than computing the VI from the average reflectance spectra (Strategy 1). As observed for $C_{a b}$ (Fig. 7), Strategy 2 enhances the influence of the heterogeneity: the latter contains little information about $C_{a b}$ variations while being strongly driven by the canopy structure, e.g., through the proportion of soil and vegetation pixels as well as that of shaded and illuminated pixels. This explains why Strategy 2 provides more accurate retrievals of these structural variables as compared to Strategy 1 . However, when the distribution of pixels is reduced, very similar results are obtained for the two strategies (Fig. 9 and Fig. 10, lines 2-4), similarly to what is observed for $C_{a b}$. Only Strategy 2 will therefore be considered in the following since it provides either best or equal GF and GAl estimation performances as Strategy 1. In the case of GF estimation, strong correlations $\left(\rho^{2} \geq 0.6\right)$ are generally obtained with all tested VIs except $m N D_{\text {blue }}[728,850]$ and $S I P I_{\text {nir }}[728,670]$ when all the pixels are considered (Fig. 9, line 1). $N D V I$ achieves the best performances for spatial resolutions close to $8 \mathrm{~cm}\left(\rho^{2}=0.93\right)$. Unlike for $\mathrm{C}_{\mathrm{ab}}$, no further improvement is observed when using only vegetation pixels (Fig. 9, lines 2-4) since, by definition, GF relates to the relative proportions of vegetation and soil.

In the case of GAl estimation when considering all the pixels, the best VIs are $\operatorname{NDVI}\left(\rho^{2}=0.86\right)$ followed by $C I_{\text {green }}$ and $N D_{550}\left(\rho^{2}=0.83\right)$ for spatial resolutions finer than $1.8 \mathrm{~cm}$ because of the beneficial influence of pure soil pixels (Fig. 10, line 1). For similar reasons as for GF estimation, focusing 
on green pixels generally decreases the performances for most resolutions and tested VIs (Fig. 10, lines 2-4), especially when considering the $50 \%$ brightest green pixels at the finest resolutions for which the impact of canopy structure is minimum. The main exceptions occur for resolutions around $8 \mathrm{~cm}$ with $N D V I, C I_{\text {green }}, N D_{550}$ and SIPI, whose performances achieved when considering the $50 \%$ darkest green pixels improve as compared to using all the pixels. The best correlation over all pixel selections is actually obtained by $N D V I$ at the $7 \mathrm{~cm}$ spatial resolution $\left(\rho^{2}=0.88\right)$. This may be due to the fact that this combination resolution/pixel selection offers the best compromise to maximize the sensitivity to canopy structure variations (maximum for the finest resolutions) while minimizing NDVI saturation (minimum for the coarsest resolutions).

These results thus demonstrate the specificities associated with each VI: most tested VIs appear to be mainly related to GF and GAI while $m N D_{\text {blue }}[728,850]$ and to a lesser extent $S I P I_{\text {nir }}[728,670]$ are strongly related to $C_{a b}$ and almost not sensitive to the structural variables. Such a result is of tremendous importance since it demonstrates that the sensitivity of $m N D_{\text {blue }}[728,850]$ to $\mathrm{C}_{\mathrm{ab}}$ will not derive from non-causal relationships due to possible covariance between $C_{a b}$ and canopy structure observed over the training dataset. 


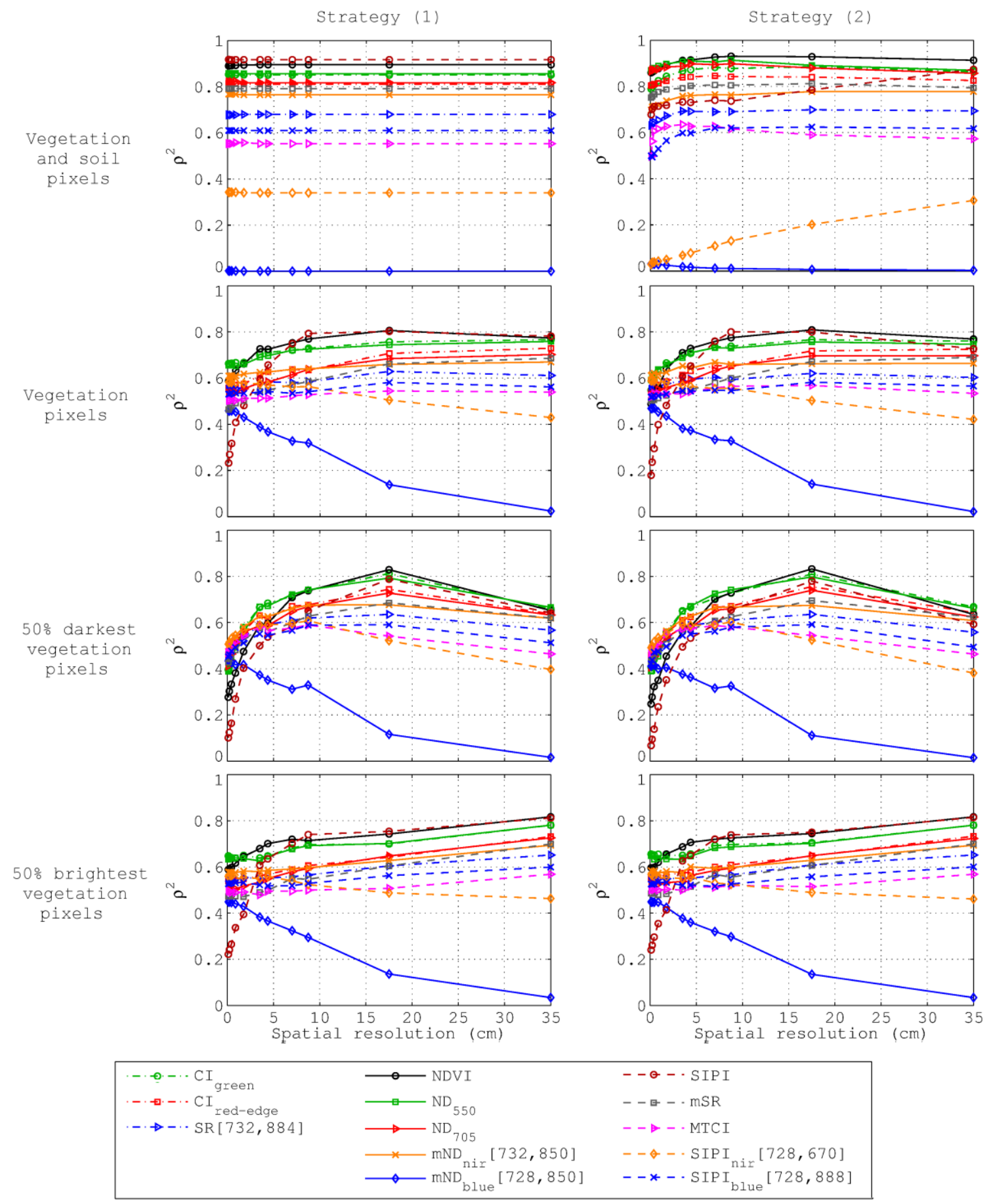

Figure 9: Squared Spearman's correlation $\left(\rho^{2}\right)$ between VIs and GF measured over the 55 plots as a function of spatial resolution. In the left-hand column, VIs are computed from the average reflectance spectra of considered pixels (strategy (1)), while in the right-hand column, VIs are computed by averaging pixel-level $\mathrm{VI}$ values (strategy (2)). For both strategies, the four subsets of pixels are tested (vegetation and soil pixels, vegetation pixels, $50 \%$ darkest and brightest vegetation pixels). 


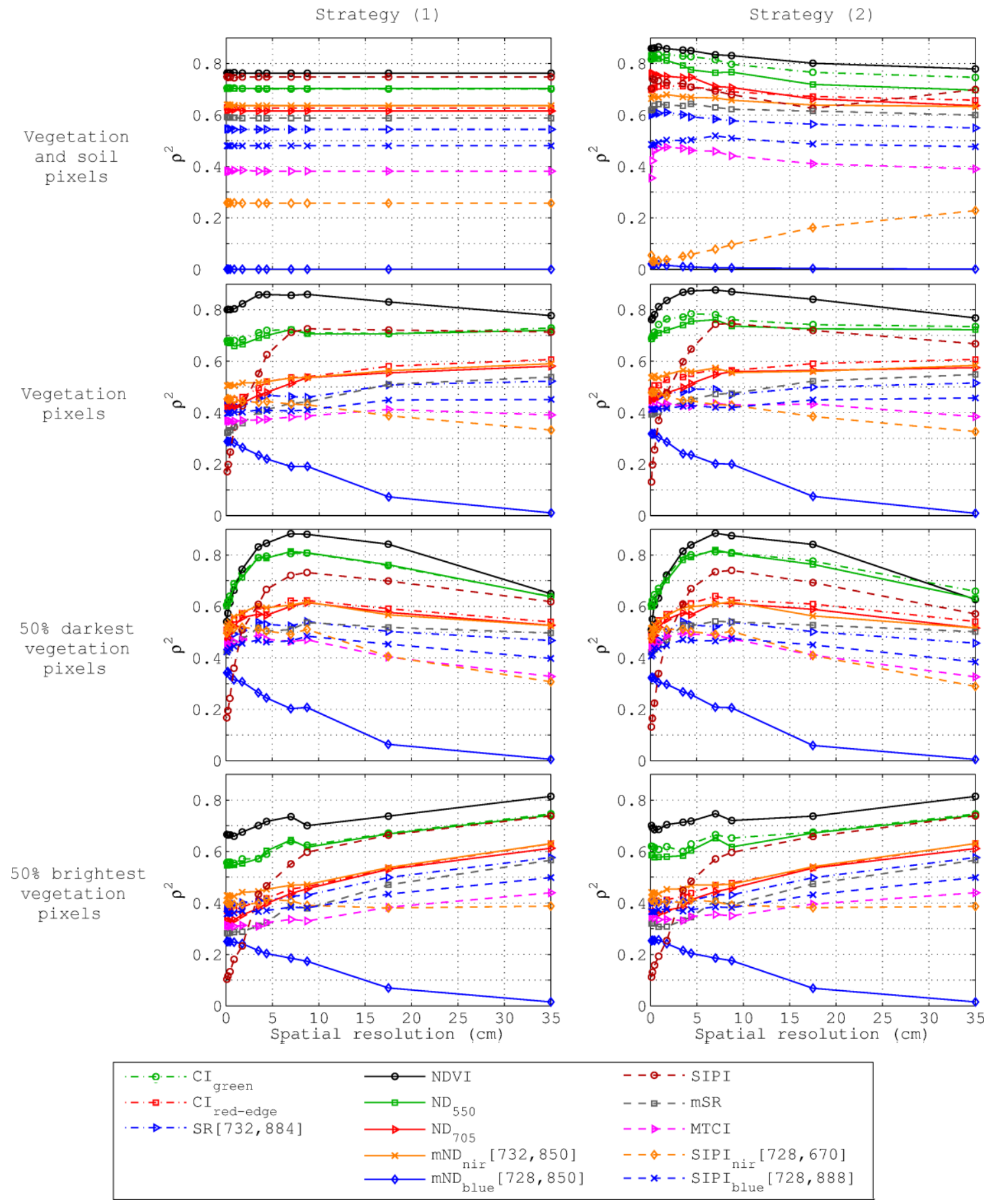

Figure 10: Squared Spearman's correlation $\left(\rho^{2}\right)$ between VIs and GAI measured over the 55 plots as a function of spatial resolution. In the left-hand column, VIs are computed from the average reflectance spectra of considered pixels (strategy (1)), while in the right-hand column, VIs are computed by averaging pixel-level $\mathrm{VI}$ values (strategy (2)). For both strategies, the four subsets of pixels are tested (vegetation and soil pixels, vegetation pixels, $50 \%$ darkest and brightest vegetation pixels). 

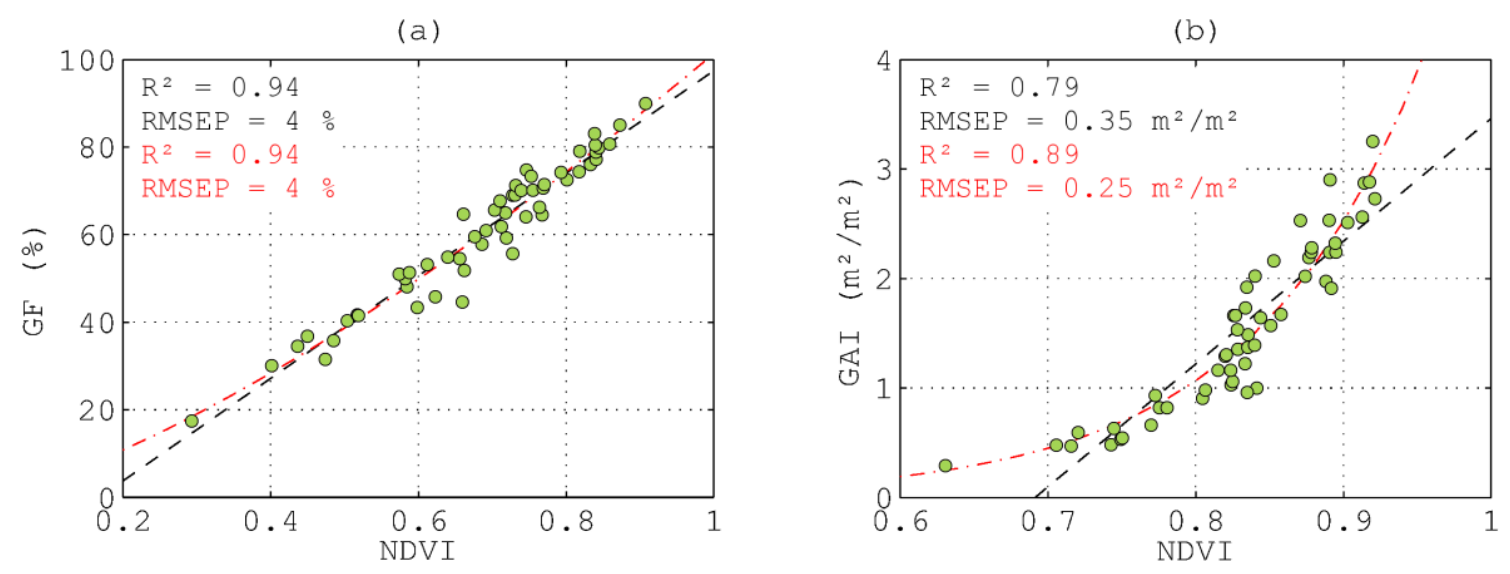

Figure 11: Relationships between NDVI and GF when considering all the pixels at the $8.8 \mathrm{~cm}$ resolution (a), and between NDVI and GAI when considering the $50 \%$ darkest green pixels at the $7 \mathrm{~cm}$ resolution (b). In both cases, VIs are computed by averaging pixel-level VI values. Prediction performances obtained using linear (in black) and best non-linear (in red, power function for GF and exponential function for GAI) regressions are shown.

The best cases observed in Fig. 9 and Fig. 10 are further detailed in Fig. 11 to quantify their performances. In the case of GF estimation, the best case corresponds to NDVI computed from all the pixels observed at the $8.8 \mathrm{~cm}$ resolution (Fig. 11.a). It obtains $R^{2}=0.94$ and $R M S E P=4 \%(5.4 \%$ of the GF range) using either linear or non-linear regression models. In the case of GAl estimation, the best case corresponds to NDVI computed over the $50 \%$ darkest green pixels observed at the $7 \mathrm{~cm}$ resolution (Fig. 11.b). While using a linear model leads to reasonable estimation results $\left(R^{2}=0.79\right.$ and $R M S E P=0.35 \mathrm{~m}^{2} / \mathrm{m}^{2}$ corresponding to $11.8 \%$ of the GAI range), using an exponential model significantly improves the performance to take into account the saturation occurring for high GAl values, as suggested by Baret and Guyot (1991) $\left(R^{2}=0.89\right.$ and $R M S E P=0.25 \mathrm{~m}^{2} / \mathrm{m}^{2}$ corresponding to $8.4 \%$ of the GAl range).

\section{Conclusions and perspectives}

This study focuses on the estimation of leaf chlorophyll content from reflectance observations using an empirical approach applied to sugar beet crops. It is clearly demonstrated that computing the spectral indices over the well-illuminated green pixels of the image improves the sensitivity to chlorophyll content and decreases the possible impact of variations in canopy structure. Further, the 
$m N D_{\text {blue }}[728,850]$ index performs significantly better than every other index tested. This index has two interesting properties: (1) as a ratio index, $m N D_{\text {blue }}[728,850]$ is by construction independent to any factor that affects the radiance reflected by the canopy in a multiplicative way, including slope effects and variations in illumination conditions due to slight cloud coverage; (2) the particular selection of wavebands enhances the sensitivity of $\operatorname{mN} D_{\text {blue }}[728,850]$ to leaf chlorophyll content while minimizing the impact of canopy structure. It is symptomatic to observe that the best-performing index for chlorophyll content estimation $\left(m N D_{\text {blue }}[728,850]\right)$ is the poorest one for canopy structure retrieval. Reciprocally, the best index for canopy structure retrieval (NDVI) offers the poorest performances for chlorophyll content estimation. The main drawback of this type of spectral index based on a blue band is its sensitivity to variations in the spectral distribution of incident light: the latter may be indeed strongly influenced by changing illumination conditions that affect the scattering by aerosols, water droplets or crystals. Great attention should therefore be paid either to the stability of irradiance conditions (using potentially artificial light sources), or to the radiometric calibration that will require frequent measurements over reference panels or corrections from ancillary information. Alternatively, the use of a red reference located in the domain of maximum chlorophyll absorption (i.e., around $680 \mathrm{~nm}$ ) may decrease the sensitivity to atmospheric conditions while providing interesting results if the spatial resolution and $\mathrm{C}_{\mathrm{ab}}$ range are such that this band nearly saturates for every sample. Incidentally, another drawback of using a blue reference is that poor estimation performances may be expected for very low values of leaf chlorophyll content, as in this case, the blue waveband does not reach saturation and varies with chlorophyll content (Sims and Gamon, 2002).

Studying the impact of spatial resolution on $\mathrm{C}_{\mathrm{ab}}$ estimation shows that $m N D_{\text {blue }}[728,850]$ may be quite sensitive to the soil influence. In the case of sugar beet crops, similar results are obtained for all the spatial resolutions finer than $4.4 \mathrm{~cm}$, but these results deteriorate for coarser resolutions. In the context of UAV-based remote sensing, this means that a resolution of about $4 \mathrm{~cm}$ offers a good compromise between accuracy and efficiency, the latter improving as spatial resolution decreases and flight altitude increases. This compromise should, however, be defined for each situation: for example, 
time constraints may be such that efficiency can be improved by reasonably decreasing spatial resolution and, therefore, accuracy (note that this decrease can somehow be compensated by choosing a shorter $\mathrm{C}_{\mathrm{ab}}$-sensitive waveband so as to mitigate the soil influence).

These results are derived from a comprehensive set of experiments including several locations, years, cultivars and levels of nitrogen fertilization. Good robustness properties are thus expected for sugar beet crops. However, these results need to be further evaluated for other species. In particular, the spatial resolution to be retained should be adapted to each crop to limit the fraction of mixed pixels in the computation of the spectral index. Also, the influence of the pixel subset used to compute the VIs should also be questioned for vegetation species exhibiting strong leaf surface effects, although this is already the case for the glossy sugar beet leaves. Ultimately, the proposed principles to derive optimal spectral indices could be extended to the estimation of other leaf biochemical constituents such as leaf water content: for example, the $C_{a b}$-sensitive waveband $(728 \mathrm{~nm})$ could be replaced by a watersensitive one.

The rapid emergence of UAVs has opened a new era of Earth observation for vegetation monitoring (Houborg et al., 2015). Multi- and hyperspectral cameras are now becoming efficient and affordable sensors, and their combination with UAVs enables the acquisition of spectral data with the required high spatial resolution while providing a significant spatial coverage capacity in a reasonable time. This is particularly interesting for agricultural applications (Duan et al., 2014; Verger et al., 2014; ZarcoTejada et al., 2013) that require a timely revisit capacity to sample the crop at the optimal development stage (Inoue et al., 2012). The VIs developed in this study take advantage of such high spatial resolution data to improve the estimation of leaf chlorophyll content in sugar beet canopies as compared to classical VIs of the literature. In particular, the use of $\operatorname{mND} D_{\text {blue }}[728,850]$ based on UAV observations is promising to accurately estimate leaf chlorophyll content over larger areas.

\section{Acknowledgments}


This study was funded by the French Ministry of Agriculture, Agrifood, and Forestry (PHENOBET project), and by the French National Research Agency, within the program "Investissements d'avenir" with the reference ANR-11-BTBR-0007 (AKER project). Thanks a lot to the three anonymous reviewers for their valuable comments and suggestions, as well as to Daniel Moura, David Bastidon and JeanFrancois Bonicel for their help in the experiments.

\section{References}

Bånkestad, D., Wik, T., 2016. Growth tracking of basil by proximal remote sensing of chlorophyll fluorescence in growth chamber and greenhouse environments. Comput. Electron. Agric. 128, 77-86. doi:10.1016/j.compag.2016.08.004

Baret, F., Buis, S., 2008. Estimating canopy characteristics from remote sensing observations: review of methods and associated problems, in: Liang, S. (Ed.), Advances in Land Remote Sensing: System, Modeling, Inversion and Application. pp. 173-201. doi:10.1007/978-1-4020-6450-0_7

Baret, F., de Solan, B., Lopez-Lozano, R., Ma, K., Weiss, M., 2010. GAl estimates of row crops from downward looking digital photos taken perpendicular to rows at $57.5^{\circ}$ zenith angle: Theoretical considerations based on 3D architecture models and application to wheat crops. Agric. For. Meteorol. 150, 1393-1401. doi:10.1016/j.agrformet.2010.04.011

Baret, F., Guyot, G., 1991. Potential and limitations of vegetation indices for LAI and APAR assessment. Remote Sens. Environ. 35, 161-173.

Blackburn, G.A., 2007. Hyperspectral remote sensing of plant pigments. J. Exp. Bot. 58, 855-867. doi:10.1093/jxb/erl123

Blackburn, G.A., 1998. Quantifying Chlorophylls and Caroteniods at Leaf and Canopy Scales. Remote Sens. Environ. 66, 273-285. doi:10.1016/S0034-4257(98)00059-5

Bousquet, L., Lachérade, S., Jacquemoud, S., Moya, I., 2005. Leaf BRDF measurements and model for 
Author-produced version of the article published in Remote Sensing of Environment, 2017, N¹98, p.173-186.

The original publication is available at http://www.sciencedirect.com

specular and diffuse components differentiation. Remote Sens. Environ. 98, 201-211.

doi:10.1016/j.rse.2005.07.005

Cerovic, Z.G., Masdoumier, G., Ghozlen, N. Ben, Latouche, G., 2012. A new optical leaf-clip meter for simultaneous non-destructive assessment of leaf chlorophyll and epidermal flavonoids. Physiol. Plant. 146, 251-260. doi:10.1111/j.1399-3054.2012.01639.x

Clevers, J., Kooistra, L., 2012. Using Hyperspectral Remote Sensing Data for Retrieving Canopy Chlorophyll and Nitrogen Content. leee J. Sel. Top. Appl. Earth Obs. Remote Sens. 5, 574-583. doi:10.1109/JSTARS.2011.2176468

Clevers, J.G.P.W., Gitelson, A.A., 2013. Remote estimation of crop and grass chlorophyll and nitrogen content using red-edge bands on sentinel-2 and-3. Int. J. Appl. Earth Obs. Geoinf. 23, 344-351. doi:10.1016/j.jag.2012.10.008

Comar, A., Baret, F., Obein, G., Simonot, L., Meneveaux, D., Viénot, F., de Solan, B., 2014. ACT: A leaf BRDF model taking into account the azimuthal anisotropy of monocotyledonous leaf surface. Remote Sens. Environ. 143, 112-121. doi:10.1016/j.rse.2013.12.006

Comar, A., Burger, P., de Solan, B., Baret, F., Daumard, F., Hanocq, J.-F., 2012. A semi-automatic system for high throughput phenotyping wheat cultivars in-field conditions: description and first results. Funct. Plant Biol. 39, 914-924. doi:10.1071/FP12065

Combal, B., Baret, F., Weiss, M., Trubuil, A., Macé, D., Pragnère, A., Myneni, R., Knyazikhin, Y., Wang, L., 2003. Retrieval of canopy biophysical variables from bidirectional reflectance: Using prior information to solve the ill-posed inverse problem. Remote Sens. Environ. 84, 1-15. doi:10.1016/S0034-4257(02)00035-4

Dash, J., Curran, P.J., 2004. The MERIS terrestrial chlorophyll index. Int. J. Remote Sens. 25, 54035413. doi:10.1080/0143116042000274015

Daughtry, C.S.., Walthall, C.., Kim, M.., de Colstoun, E.B., McMurtrey, J.., 2000. Estimating Corn Leaf 
Author-produced version of the article published in Remote Sensing of Environment, 2017, N¹98, p.173-186.

The original publication is available at http://www.sciencedirect.com Doi: 10.1016/j.rse.2017.06.008

Chlorophyll Concentration from Leaf and Canopy Reflectance. Remote Sens. Environ. 74, 229239. doi:10.1016/S0034-4257(00)00113-9

Dorigo, W. a., 2012. Improving the robustness of cotton status characterisation by radiative transfer model inversion of multi-angular CHRIS/PROBA data. IEEE J. Sel. Top. Appl. Earth Obs. Remote Sens. 5, 18-29. doi:10.1109/JSTARS.2011.2171181

Duan, S.B., Li, Z.L., Wu, H., Tang, B.H., Ma, L., Zhao, E., Li, C., 2014. Inversion of the PROSAIL model to estimate leaf area index of maize, potato, and sunflower fields from unmanned aerial vehicle hyperspectral data. Int. J. Appl. Earth Obs. Geoinf. 26, 12-20. doi:10.1016/j.jag.2013.05.007

Elarab, M., Ticlavilca, A.M., Torres-Rua, A.F., Maslova, I., McKee, M., 2015. Estimating chlorophyll with thermal and broadband multispectral high resolution imagery from an unmanned aerial system using relevance vector machines for precision agriculture. Int. J. Appl. Earth Obs. Geoinf. 43, 32-42. doi:10.1016/j.jag.2015.03.017

Féret, J.-B., François, C., Gitelson, A., Asner, G.P., Barry, K.M., Panigada, C., Richardson, A.D., Jacquemoud, S., 2011. Optimizing spectral indices and chemometric analysis of leaf chemical properties using radiative transfer modeling. Remote Sens. Environ. 115, 2742-2750. doi:10.1016/j.rse.2011.06.016

Gitelson, A.A., Gritz, Y., Merzlyak, M.N., 2003. Relationships between leaf chlorophyll content and spectral reflectance and algorithms for non-destructive chlorophyll assessment in higher plant leaves. J. Plant Physiol. 160, 271-282. doi:10.1078/0176-1617-00887

Gitelson, A.A., Kaufman, Y.J., Merzlyak, M.N., 1996. Use of a green channel in remote sensing of global vegetation from EOS-MODIS. Remote Sens. Environ. 58, 289-298. doi:10.1016/S00344257(96)00072-7

Gitelson, A.A., Keydan, G.P., Merzlyak, M.N., 2006. Three-band model for noninvasive estimation of chlorophyll, carotenoids, and anthocyanin contents in higher plant leaves. Geophys. Res. Lett. 
Author-produced version of the article published in Remote Sensing of Environment, 2017, N¹98, p.173-186.

The original publication is available at http://www.sciencedirect.com

33, 1-6. doi:10.1029/2006GL026457

Gitelson, A.A., Merzlyak, M.N., 1994. Spectral Reflectance Changes Associated with Autumn Senescence of Aesculus-hippocastanum L. and Acer-platanoides L. Leaves - Spectral Features and Relation to Chlorophyll Estimation. J. Plant Physiol. 143, 286-292. doi:10.1016/S0176$1617(11) 81633-0$

Gitelson, A.A., Vina, A., Ciganda, V., Rundquist, D.C., Arkebauer, T.J., 2005. Remote estimation of canopy chlorophyll content in crops. Geophys. Res. Lett. 32, 1-4. doi:10.1029/2005GL022688

Haboudane, D., Miller, J.R., Tremblay, N., Zarco-Tejada, P.J., Dextraze, L., 2002. Integrated narrowband vegetation indices for prediction of crop chlorophyll content for application to precision agriculture. Remote Sens. Environ. 81, 416-426. doi:10.1016/S0034-4257(02)00018-4

Haboudane, D., Tremblay, N., Miller, J.R., Vigneault, P., 2008. Remote estimation of crop chlorophyll content using spectral indices derived from hyperspectral data. IEEE Trans. Geosci. Remote Sens. 46, 423-436. doi:10.1109/TGRS.2007.904836

Houborg, R., Fisher, J.B., Skidmore, A.K., 2015. Advances in remote sensing of vegetation function and traits. Int. J. Appl. Earth Obs. Geoinf. 43, 1-6. doi:10.1016/j.jag.2015.06.001

Hunt, E.R., Doraiswamy, P.C., McMurtrey, J.E., Daughtry, C.S.T., Perry, E.M., Akhmedov, B., 2012. A visible band index for remote sensing leaf chlorophyll content at the canopy scale. Int. J. Appl. Earth Obs. Geoinf. 21, 103-112. doi:10.1016/j.jag.2012.07.020

Inoue, Y., Sakaiya, E., Zhu, Y., Takahashi, W., 2012. Diagnostic mapping of canopy nitrogen content in rice based on hyperspectral measurements. Remote Sens. Environ. 126, 210-221. doi:10.1016/j.rse.2012.08.026

Jacquemoud, S., Baret, F., 1990. PROSPECT: A model of leaf optical properties spectra. Remote Sens. Environ. 34, 75-91. doi:10.1016/0034-4257(90)90100-Z 
Author-produced version of the article published in Remote Sensing of Environment, 2017, N¹98, p.173-186.

The original publication is available at http://www.sciencedirect.com

Jacquemoud, S., Verhoef, W., Baret, F., Bacour, C., Zarco-Tejada, P.J., Asner, G.P., François, C., Ustin, S.L., 2009. PROSPECT+SAIL models: A review of use for vegetation characterization. Remote Sens. Environ. 113, S56-S66. doi:10.1016/j.rse.2008.01.026

Jay, S., Bendoula, R., Hadoux, X., Féret, J.-B., Gorretta, N., 2016. A physically-based model for retrieving foliar biochemistry and leaf orientation using close-range imaging spectroscopy. Remote Sens. Environ. 177, 220-236. doi:http://dx.doi.org/10.1016/j.rse.2016.02.029

Jay, S., Maupas, F., Bendoula, R., Gorretta, N., n.d. Retrieving LAI, chlorophyll and nitrogen contents in sugar beet crops from multi-angular optical remote sensing: comparison of vegetation indices and PROSAIL inversion for field phenotyping. F. Crop. Res. submitted.

Knyazikhin, Y., Schull, M. a, Stenberg, P., Mõttus, M., Rautiainen, M., Yang, Y., Marshak, A., Latorre Carmona, P., Kaufmann, R.K., Lewis, P., Disney, M.I., Vanderbilt, V., Davis, A.B., Baret, F., Jacquemoud, S., Lyapustin, A., Myneni, R.B., 2013. Hyperspectral remote sensing of foliar nitrogen content. Proc. Natl. Acad. Sci. U. S. A. 110, E185-92. doi:10.1073/pnas.1210196109

Kooistra, L., Clevers, J.G.P.W., 2016. Estimating potato leaf chlorophyll content using ratio vegetation indices. Remote Sens. Lett. 7, 611-620. doi:10.1080/2150704X.2016.1171925

Latorre-Carmona, P., Knyazikhin, Y., Alonso, L., Moreno, J.F., Pla, F., Yan, Y., 2014. On hyperspectral remote sensing of leaf biophysical constituents: Decoupling vegetation structure and leaf optics using CHRIS-PROBA data over crops in barrax. IEEE Geosci. Remote Sens. Lett. 11, 1579-1583. doi:10.1109/LGRS.2014.2305168

le Maire, G., François, C., Dufrêne, E., 2004. Towards universal broad leaf chlorophyll indices using PROSPECT simulated database and hyperspectral reflectance measurements. Remote Sens. Environ. 89, 1-28. doi:10.1016/j.rse.2003.09.004

Moorthy, I., Miller, J.R., Noland, T.L., 2008. Estimating chlorophyll concentration in conifer needles with hyperspectral data: An assessment at the needle and canopy level. Remote Sens. Environ. 
Author-produced version of the article published in Remote Sensing of Environment, 2017, N¹98, p.173-186.

The original publication is available at http://www.sciencedirect.com

112, 2824-2838. doi:10.1016/j.rse.2008.01.013

Penuelas, J., Baret, F., Filella, I., 1995. Semi-empirical indices to assess carotenoids/chlorophyll a ratio from leaf spectral reflectance. Photosynthetica 31, 221-230.

Rondeaux, G., Steven, M., Baret, F., 1996. Optimization of soil-adjusted vegetation indices. Remote Sens. Environ. 55, 95-107. doi:10.1016/0034-4257(95)00186-7

Rondeaux, G., Vanderbilt, V.C., 1993. Specularly modified vegetation indices to estimate photosynthetic activity . Int. J. Remote Sens. doi:10.1080/01431169308954004

Rouse, J.W., Hass, R.H., Schell, J.A., Deering, D.W., 1973. Monitoring vegetation systems in the great plains with ERTS. Third Earth Resour. Technol. Satell. Symp. 1, 309-317. doi:citeulike-articleid:12009708

Schlemmer, M., Gitelson, a., Schepers, J., Ferguson, R., Peng, Y., Shanahan, J., Rundquist, D., 2013. Remote estimation of nitrogen and chlorophyll contents in maize at leaf and canopy levels. Int. J. Appl. Earth Obs. Geoinf. 25, 47-54. doi:10.1016/j.jag.2013.04.003

Sims, D.A., Gamon, J.A., 2002. Relationships between leaf pigment content and spectral reflectance across a wide range of species, leaf structures and developmental stages. Remote Sens. Environ. 81, 337-354. doi:10.1016/S0034-4257(02)00010-X

Steven, M., Malthus, T., Baret, F., 2015. Toward Standardization of Vegetation Indices, in: Thenkabail, P.S. (Ed.), Remotely Sensed Data Characterization, Classification, and Accuracies. CRC Press, pp. 175-194. doi:doi:10.1201/b19294-13

Ustin, S.L., 2013. Remote sensing of canopy chemistry. Proc. Natl. Acad. Sci. U. S. A. 110, 804-5. doi:10.1073/pnas.1219393110

Ustin, S.L., Gitelson, a. a., Jacquemoud, S., Schaepman, M., Asner, G.P., Gamon, J. a., Zarco-Tejada, P., 2009. Retrieval of foliar information about plant pigment systems from high resolution 
Author-produced version of the article published in Remote Sensing of Environment, 2017, N¹98, p.173-186.

The original publication is available at http://www.sciencedirect.com Doi: 10.1016/j.rse.2017.06.008

spectroscopy. Remote Sens. Environ. 113, S67-S77. doi:10.1016/j.rse.2008.10.019

Verger, A., Vigneau, N., Chéron, C., Gilliot, J.M., Comar, A., Baret, F., 2014. Green area index from an unmanned aerial system over wheat and rapeseed crops. Remote Sens. Environ. 152, 654-664. doi:10.1016/j.rse.2014.06.006

Vigneau, N., Ecarnot, M., Rabatel, G., Roumet, P., 2011. Potential of field hyperspectral imaging as a non destructive method to assess leaf nitrogen content in Wheat. F. Crop. Res. 122, 25-31. doi:10.1016/j.fcr.2011.02.003

Wu, C., Niu, Z., Tang, Q., Huang, W., 2008. Estimating chlorophyll content from hyperspectral vegetation indices: Modeling and validation. Agric. For. Meteorol. 148, 1230-1241. doi:10.1016/j.agrformet.2008.03.005

Zarco-Tejada, P.., Miller, J.., Morales, A., Berjón, A., Agüera, J., 2004. Hyperspectral indices and model simulation for chlorophyll estimation in open-canopy tree crops. Remote Sens. Environ. 90, 463-476. doi:10.1016/j.rse.2004.01.017

Zarco-Tejada, P.J., Guillén-Climent, M.L., Hernández-Clemente, R., Catalina, A., González, M.R., Martín, P., 2013. Estimating leaf carotenoid content in vineyards using high resolution hyperspectral imagery acquired from an unmanned aerial vehicle (UAV). Agric. For. Meteorol. 171, 281-294. doi:10.1016/j.agrformet.2012.12.013

Zarco-Tejada, P.J., Miller, J.R., Noland, T.L., Mohammed, G.H., Sampson, P.H., 2001. Scaling-up and model inversion methods with narrowband optical indices for chlorophyll content estimation in closed forest canopies with hyperspectral data. IEEE Trans. Geosci. Remote Sens. 39, 14911507. doi:10.1109/36.934080 